\title{
Extraction Process Optimization, Identification, and Profiling of Phenolic Antioxidant Compounds from the Fruits of Ficus auriculata
}

\section{Shahinuzzaman}

Department of Chemical Sciences, Faculty of Science and Technology, Universiti Kebangsaaan Malaysia, 43600 UKM Bangi, Selangor, Malaysia

\section{Parul Akhtar}

Department of Chemistry, Chittagong University of Engineering \& Technology, Chittagong-4349, Bangladesh

\section{N. Amin}

Institute of Sustainable Energy, Universiti Tenaga Nasional (@The National Energy University), Jalan IKRAM-UNITEN, 43000 Kajang, Selangor, Malaysia

\section{Yunus Ahmed}

Department of Chemistry, Chittagong University of Engineering \& Technology, Chittagong-4349, Bangladesh

\section{Farah Anuar}

Department of Chemical Sciences, Faculty of Science and Technology, Universiti Kebangsaaan Malaysia, 43600 UKM Bangi, Selangor, Malaysia

\section{H. Misran}

Institute of Sustainable Energy, Universiti Tenaga Nasional (@The National Energy University), Jalan IKRAM-UNITEN, 43000 Kajang, Selangor, Malaysia

\section{Md. Akhtaruzzaman ( $\square$ akhtar@ukm.edu.my)}

Solar Energy Research Institute, Universiti Kebangsaan Malaysia, Bangi 43600, Selangor, Malaysia

\section{Research Article}

Keywords: Antioxidant activity, Ficus auriculata, Optimization, Mass spectrometry, Phenolic compounds

Posted Date: December 1st, 2020

DOI: https://doi.org/10.21203/rs.3.rs-113810/v1

License: (a) (i) This work is licensed under a Creative Commons Attribution 4.0 International License. Read Full License 
1 Extraction Process Optimization, Identification, and Profiling of Phenolic Antioxidant Compounds from the Fruits of Ficus auriculata

M. Shahinuzzaman', Parul Akhtar², N. Amin ${ }^{3}$, Yunus Ahmed ${ }^{2}$, Farah Hannan Anuar', 5

H. Misran ${ }^{3}$, and Md. Akhtaruzzaman, ${ }^{4 *}$

6

$7 \quad{ }^{1}$ Department of Chemical Sciences, Faculty of Science and Technology, Universiti

8 Kebangsaaan Malaysia, 43600 UKM Bangi, Selangor, Malaysia

$9{ }^{2}$ Department of Chemistry, Chittagong University of Engineering \& Technology, Chittagong10 4349, Bangladesh

$11{ }^{3}$ Institute of Sustainable Energy, Universiti Tenaga Nasional (@The National Energy

12 University), Jalan IKRAM-UNITEN, 43000 Kajang, Selangor, Malaysia.

$13{ }^{4}$ Solar Energy Research Institute, Universiti Kebangsaan Malaysia, Bangi 43600, Selangor,

14 Malaysia

15

16

* Corresponding authors:

Md. Akhtaruzzaman,

Email: akhtar@ukm.edu.my; Tel: +60193217560, +603-89118587 Fax: +60389118574 


\section{$1 \quad$ Abstract}

2 In this study, the extraction conditions to maximize the antioxidant activity and total phenolic

3 content of Ficus auriculata were optimized using response surface methodology. For the purpose of extraction, the Ultrasonic assisted extraction technique was employed. A secondorder polynomial model satisfactorily fitted to the experimental findings concerning antioxidant activity $\left(\mathrm{R}^{2}=0.968, P<0.0001\right)$ and total phenolic content $\left(\mathrm{R}^{2}=0.961, P<0.0001\right)$, indicating a significant correlation between the experimental and expected value. The highest antioxidant activity $(85.20 \pm 0.96 \%)$ for DPPH were achieved at the optimum extraction parameters of $52.5 \%$ ethanol $(\mathrm{v} / \mathrm{v}), 40.0{ }^{\circ} \mathrm{C}$ temperature, and $22 \mathrm{~min}$ extraction time. Alternatively, the highest yield of total phenolic content was found $31.65 \pm 0.94 \mathrm{mg} \mathrm{GAE} / \mathrm{g}$ DF at the optimum extraction conditions. From the LC-ESI-MS profiling of the optimized extract, 18 bioactive compounds were tentatively identified, which may regulate the antioxidant activity of fruits of $F$. auriculata.

\section{Keywords}

Antioxidant activity; Ficus auriculata; Optimization; Mass spectrometry; Phenolic compounds

\section{Introduction}

The human body is vulnerable to reactive oxygen species (ROS). Natural antioxidants are an essential compound for reducing the concentration of these species and prevent various chronic disorders like cancer, rheumatoid arthritis, atherosclerosis, emphysema, cirrhosis, diabetes and others, which cause free radical ( ${ }^{\circ} \mathrm{OH},{ }^{1} \mathrm{O}_{2}, \mathrm{O}_{2}{ }^{\cdot-}$, ) and non-free radical ( $\mathrm{R}-\mathrm{OOH}, \mathrm{NO}, \mathrm{ONOO}^{-}$, and $\mathrm{H}_{2} \mathrm{O}_{2}$ ) ROS species ${ }^{1,2}$. Besides the body's endogenous antioxidant defence, antioxidants are primarily derived from diet and can promote good health. Numerous synthetic antioxidants are commonly used in different food products, but these products are restricted due to their carcinogenic and other toxic properties ${ }^{3}$. In addition, there is a demand for natural antioxidants as food preservatives to reduce oxidation and rancidity of foods. Therefore, the attention of natural antioxidants has been raised considerably in the study of certain fruits, vegetables and leaves with high antioxidant contents to boost their consumption. Consequently, an effective extraction technique and the optimization of the extraction conditions are very important for the exploitation of antioxidant phenolic compounds. It may enable to obtain natural antioxidants in larger quantities and reduce costs. 
1 Ficus auriculata Lour., a member of the Moraceae family, is a naturally grown plant in 2 lowland tropical rainforests, along streams or on rocks. It is also known as Elephant ear fig or 3 Roxburgh fig ${ }^{4}$. Its crude extract exhibited antioxidant, antibacterial, antimicrobial, antihyperlipidemic, hepatoprotective activity as well as contain a higher amount of flavonoid content $^{5-8}$. Fruits of $F$. auriculata are not only valuable for its nutritional value but also contains a higher amount of phenolic compounds as compared to other parts. Our previous study found that the leaves, barks and fruits of $F$. auriculata exhibited 93.78 $\pm 0.83,87.30 \pm 1.29$ and $89.40 \pm 0.83 \%$ of inhibition of DPPH as well as $99.66 \pm 0.55,98.55 \pm 0.73$ and $96.47 \pm 0.83 \%$ of ABTS scavenging activity using ultrasonic assisted extraction process ${ }^{9}$. Moreover, most of the extracts from $F$. auriculata obtained by ultrasound assisted extraction (UAE) process, showed the highest antioxidant activity, phenolic contents and extraction yields as compared to the maceration process ${ }^{9}$. In 2014, Hlail and co-workers reported similar phenomena for the fruits to extract, which exhibited higher Biological activity compared to leaves extract ${ }^{10}$.

Numerous extraction techniques have been evolved and used to isolate the bioactive antioxidant compounds from plant sources. Among these techniques, maceration extraction ${ }^{3,11}$, microwave-assisted extraction ${ }^{12,13}$ and supercritical fluid extraction ${ }^{14,15}$ are now used. In the first case, it is time wasting and requires relatively large amounts of solvents. The supercritical fluid extraction process is not economically viable due to the higher cost of the equipment and blockage the systems due to the use of water as the solvent. By considering the concept of "green chemistry", environment-friendly techniques are required for the determination of antioxidant compounds. Ultrasonic assisted extraction (UAE) is an eco- friendly method, which offers high extraction efficiency, good reproducibility in lower extraction times and requires relatively low solvent, temperature and energy input. This method can be easily scaled up for industrial applications ${ }^{16}$. Ultrasound provokes a formation of tiny bubbles exposed to fast adiabatic expansions and compressions, which rises the temperatures and pressures within the system ${ }^{11}$. Thus, the ultrasound irradiation process could contribute to the higher yields of phenolic content. However, sonication process swells dried plants by adsorbing a higher amount extraction solvent ${ }^{17}$ as a result of enlarged pores of cell walls that permit greater diffusivity across the cell walls. Finally, the process breakdown the cell walls, which enable to wash out the cell content and allow higher efficiency to release the phenolic and antioxidant active compounds ${ }^{18-20}$.

In general, process optimization could be achieved through either statistical or experimental method ${ }^{21,22}$. The experiential technique involves the study of one-factor-at-a-time which is that all the variables are kept at constant and only one variable changes ${ }^{23}$. The major 
1 weakness of this method that it ignored the interactive effects among the individual variables and the ambiguous decision may be drawn. It also increases the experimental run to conduct the research that is laborious, time-consuming and raise the solvent and materials consumption $^{24}$. So, it is needed to establish the optimum process to recover the highest numbers of bioactive compounds with conserved all the functional parameters.

Among the various Response surface methodology (RSM) designs, Central composite design (CCD) is an efficient system which is timesaving and more competent among others. It is very much helpful to develop, improve and optimize extraction conditions of natural antioxidants and plant metabolites ${ }^{25,26}$. Nevertheless, the feasibility of extraction process for $F$. auriculata has not been explored yet.

Therefore, the purpose of this study was to optimize the extraction parameters to obtain maximum antioxidant activity and phenolic content from the fruits of $F$. auriculata using UAE and RSM with a CCD. Finally, the phenolic profile of the most active extract was comprehensively studied by liquid chromatography (LC) coupled to mass spectrometry (MS) via electrospray ionization (ESI).

\section{Material and Methods}

Chemicals and reagents. 1,1-Diphenyl-2-picrylhydrazyl (DPPH) and 2,2'-azinobis-(3ethylbenzothiazoline-6-sulfonic acid) (ABTS) were purchased from Sigma-Aldrich (St. Louis, MO, USA). Folin-Ciocalteu reagent was purchased from Merck, Germany. Potassium persulfate, $99.9 \%$ pure ethanol, monohydrate gallic acid and anhydrous sodium carbonate were purchased from Friendemann Schmidt (FS) Chemicals, Australia. All the chemicals which were used in this study were in analytical grade. The $18 \mathrm{~m} \Omega$ deionised water was used to prepare standard materials and extraction.

The fresh fruit samples of $F$. auriculata were picked up from the main campus of Universiti Kebangsaan Malaysia, 43600 Bangi, Selangor, Malaysia (Figure 1).

28 The fruits were cleaned properly with distilled water and then dried at $45-50{ }^{\circ} \mathrm{C}$ with the help of Septree Food Dehydrator. Finally, all the fruits were powdered using a special grinder (XY2200B, Shenzhen Yason General Machinery Co., Ltd, Guangdong, China) and stored in an airtight container. 


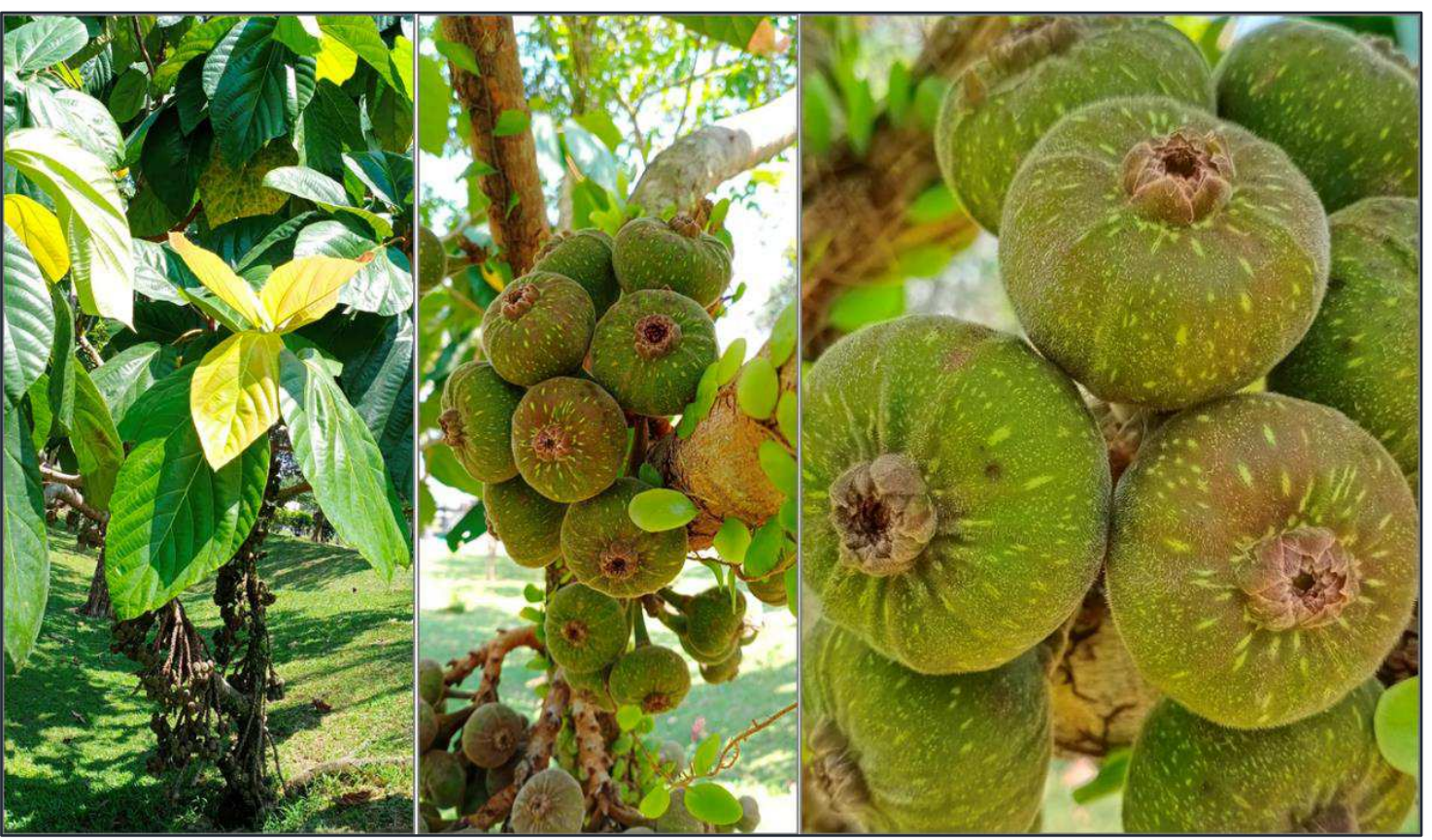

4 Extraction procedures. The extraction of the fruits of $F$. auriculata was executed in 5 Thermo-line ultrasonic bath $(220 \mathrm{~V}$ and $40 \mathrm{kHz})$ at $35^{\circ} \mathrm{C}$. Two hundred fifty $\mathrm{mg}$ of dried and 6 ground powdered sample was transferred into a capped long test-tube $(50 \mathrm{~mL})$ and $10 \mathrm{~mL}$ of

Figure 1. Fresh fruits of Ficus auriculate collected from UKM campus 
(a)

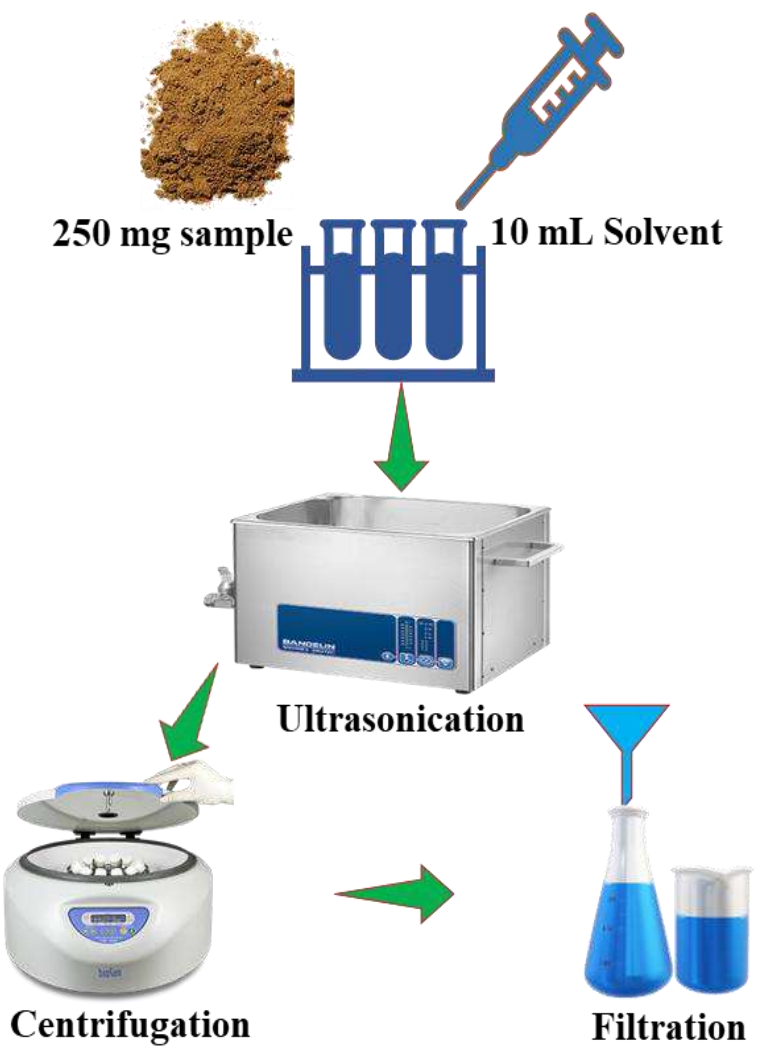

(b)

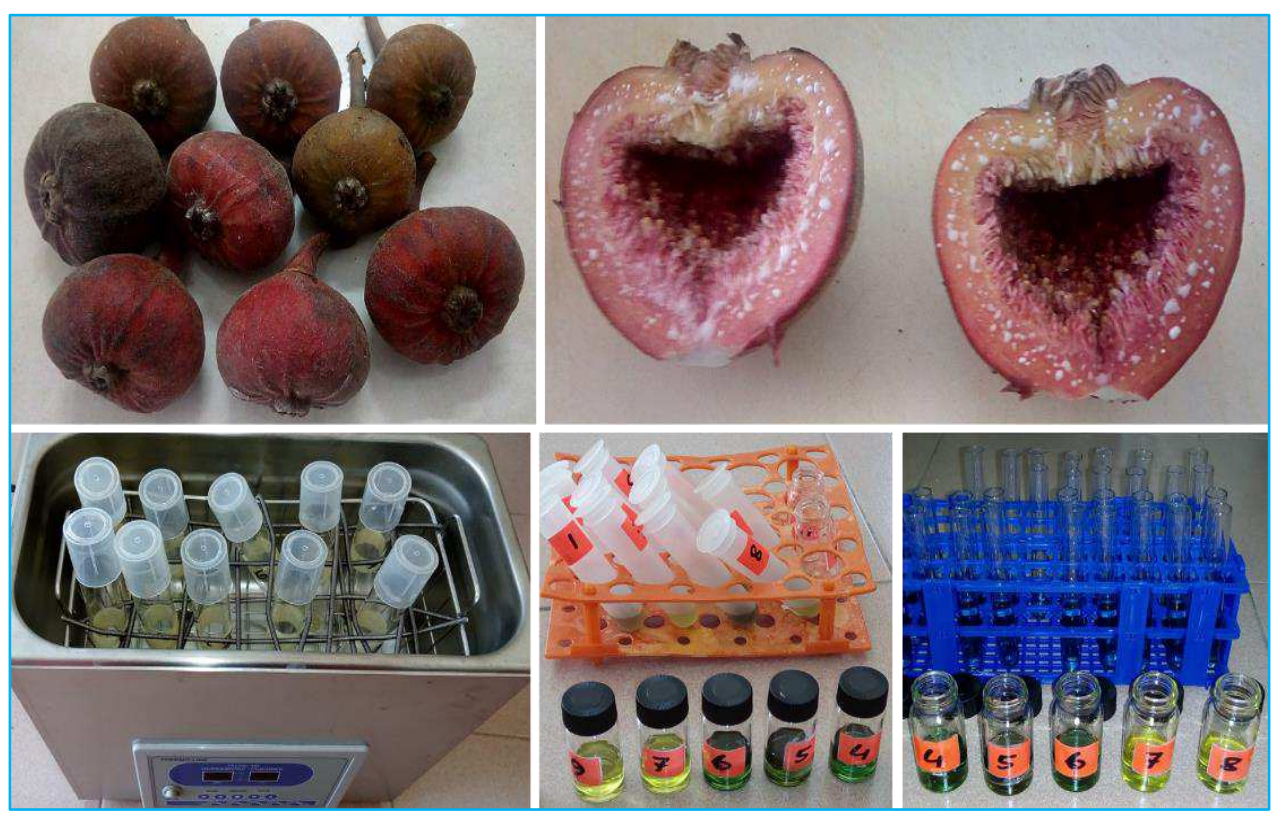

Figure 2. a) Schematic diagram for extraction and b) Extraction process of antioxidant active compounds from $F$. auriculata fruits 


\section{Antioxidant activity analysis}

2 DPPH assay. The DPPH antioxidant activity of fruits extract of F. auriculata were measured 3 by using some reported method with some modifications ${ }^{27}$. In brief, $0.1 \mathrm{mM}$ of fresh DPPH 4 was prepared with $70 \%$ of aqueous ethanol. The $100 \mu \mathrm{L}$ of different standard Trolox solution

5 (positive control) and the sample were added to $3.9 \mathrm{~mL} \mathrm{DPPH}$ solution $(0.1 \mathrm{mM})$. Then, the 6 control, and sample absorbance were recorded at $520 \mathrm{~nm}$ after incubated 30 minutes at dark 7 conditions and room temperatures. The DPPH scavenging activity (percentage of inhibition) 8 was calculated by using the equation below:

Antioxidant capacity $(\%$ inhibition $)=\left[\left(\mathrm{A}_{\mathrm{C}}-\mathrm{A}_{\mathrm{S}}\right) / \mathrm{A}_{\mathrm{S}}\right] \times 100$

Where $A_{C}$ is the absorbance of a radical solution with $70 \%$ of aqueous ethanol; $A_{S}$ is the absorbance of radical solution mixed with sample or standard. Each sample and standard were measured in three replications. The absorbance was measured with 756 PC UV-Visible spectrophotometer.

ABTS $^{+}$assay. The ABTS radical scavenging assay was calculated based on the method described by S. Gorinstein et al. ${ }^{28}$ with little modifications. At first the $7 \mathrm{mM}$ ABTS solution using water was prepared and mixed with $2.45 \mathrm{mM}$ potassium persulfate $\left(\mathrm{K}_{2} \mathrm{~S}_{2} \mathrm{O}_{8}\right)$ solution with same ratio to get the free radical solution ${ }^{29}$. In dark condition at room temperature, the mixture was stored for 12-16 hours. To carry out each bioassay, the fresh working solution was then made by diluting $1 \mathrm{~mL}$ ABTS radical solution with the amount of ethanol needed to achieve an absorbance of $0.700 \pm 0.02$ units at the wavelength of $745 \mathrm{~nm}$. After that, $100 \mu \mathrm{L}$ of different standard Trolox solution and extracts sample was added to $3.9 \mathrm{~mL}$ of an $\mathrm{ABTS}^{+}$ solution and incubated 6 minutes at room temperature. Finally, the control and sample absorbance were instantly assessed at $745 \mathrm{~nm}$. Here, Trolox is the positive control and $70 \%$ of aqueous ethanol is used as blank. Finally the equation 1 was used to calculate the inhibitiob percentage. The equipment used was described before. 
1 Total phenolic content (TPC) assessment. The TPC of fruits of $F$. auriculata was assessed using Folin-Ciocalteu (FC) reagent with a little modification ${ }^{30}$. Prior to use the FC reagent were diluted at 20 times. Then the $100 \mu \mathrm{L}$ of gallic acid or extract samples were properly added with $3.4 \mathrm{~mL}$ of FC reagent and kept for $7 \mathrm{~min}$. A $500 \mu \mathrm{L}$ of $\mathrm{Na}_{2} \mathrm{CO}_{3}(20 \%)$ was then added to the reaction mixture and incubated at room temperature in a dark place for 2 hours. The absorbance was finally determined at $760 \mathrm{~nm}$ from a standard gallic acid curve of $31.25 \mu \mathrm{g} / \mathrm{mL}$ to 1.0 $\mathrm{mg} / \mathrm{mL}$. The outcomes of the TPC were presented as $\mathrm{mg}$ gallic acid equivalent (GAE)/g dry fruits (DF). Each experiment was done as triplicate. The equipment used was as for previous assays. variables viz. solvent concentration $(\mathrm{X} 1, \%, \mathrm{v} / \mathrm{v})$; extraction temperature $\left(\mathrm{X} 2,{ }^{\circ} \mathrm{C}\right)$ and sonication time (X3, min) at five different levels with responses of two dependent variables such as antioxidant activity (DPPH assay) and TPC (Table 1). The design comprising of 20 experimental runs involving 8 factorial points, 6 axial points and 6 centre points. The secondorder polynomial model in the response surface analysis is demonstrated using the equation

$$
\mathrm{Y}=B_{0}+\sum_{i=1}^{n} B_{i} X_{i}+\sum_{i<j}^{n} B_{i j} X_{i} X_{j}+\sum_{j=1}^{n} B_{j j} X_{j}^{2}
$$

Where $Y$ is the response function of the independent variables; $B_{0}$ is a constant, $B_{i}$ is the linear coefficient, $B_{\mathrm{ij}}$ is the second-order interaction, and $B_{\mathrm{jj}}$ is the quadratic coefficients. The variable, $X_{i}$ is the non-coded independent variables. Here, three independent variables were used and hence $n$ equal to 3. Thus, equation (2) is expressed with equation (3):

$$
Y=B_{0}+B_{1} X_{1}+B_{2} X_{2}+B_{3} X_{3}+B_{12} X_{1} X_{2}+B_{13} X_{1} X_{3}+B_{23} X_{2} X_{3}+B_{11} X_{1}^{2}+B_{22} X^{2}{ }_{2}+B_{33} X^{2}{ }_{3}
$$

Where $\mathrm{Y}$ represents the predicted response (antioxidant activity and TPC), and $\mathrm{X}_{1}, \mathrm{X}_{2}$ and $\mathrm{X}_{3}$ are independent variables. $B_{0}$ is a constant and $B_{1}, B_{2}$ and $B_{3}$ are linear coefficients. $B_{12}$, $B_{13}$ and $B_{23}$ are cross coefficients and $B_{11}, B_{22}$ and $B_{33}$ are quadratic coefficients. 
2 Table 1. Control variables, their coded values and actual values included in optimisation

\begin{tabular}{lccccccc}
\hline \multirow{2}{*}{ Control variables } & \multirow{2}{*}{ Units } & \multirow{2}{*}{ Symbol } & \multicolumn{5}{c}{ Coded levels } \\
\cline { 4 - 8 } Ethanol concentration & $\%, \mathrm{v} / \mathrm{v}$ & $\mathrm{X}_{1}$ & 7.95 & 25 & 50 & 75 & 92.04 \\
Temperature & ${ }^{\circ} \mathrm{C}$ & $\mathrm{X}_{2}$ & 14.77 & 25 & 40 & 55 & 65.22 \\
Sonication time & $\min$ & $\mathrm{X}_{3}$ & 3.18 & 10 & 20 & 30 & 36.81 \\
\hline
\end{tabular}

3

4 Statistical analysis. Analysis of variance (ANOVA) was used to verify the statistical validity 5 of the response surface quadratic model coefficients and the Design-Expert 6.0.6 (Stat-Ease,

6 Inc., USA) was used to conduct the data analysis. The regression coefficient $\left(R^{2}\right)$ along with 7 the $F$-test, was assessed to test the fit of the polynomial model. The statistical significances for 8 different terms in the polynomial model were evaluated by the estimation of $F$-value with 9 different probability $(P)$ range such as $0.001,0.01$ or $0.05 . P$ values less than 0.05 and 0.01 10 indicate that the value is statistically significant and very significant. The \% of DPPH inhibition and GAE curve was done using Microsoft Excel 16 (Microsoft Inc., Redmond, USA).

Determination of bioactive compounds via LC-ESI-MS studies.

The bioactive

14 phenolic compounds were profiled using LC-MS using the mass analyzer Bruker micrOTOFQ. A reverse phase C18 column (Phenomenex $250 \mathrm{~mm}, 5 \mu \mathrm{m}$ particle size) was used. The eluting system consisted of water acidified with $0.1 \%$ formic acid and $(1: 1, \mathrm{v} / \mathrm{v})$ acetonitrile/methanol acidified with $0.1 \%$ formic acid as solvent $\mathrm{A}$ and $\mathrm{B}$ respectively. The $0.45 \mu \mathrm{m}$ membrane disk filter was used to filter the mobile phase and degassed by sonication before injection. The parameters which were used to the Elution process are as follows: $5 \% \mathrm{~B}$, $0-5 \mathrm{~min} ; 5 \%-10 \%$

B, 5-10 min; $10 \%-50 \%$

B, 10-55 $\min ; 50 \%-95 \%$

B, 55-65 min; 5\% B, 65-70 min. The $20 \mu \mathrm{L}$ of solvent was injected with $0.4 \mathrm{~mL} / \mathrm{min}$ flow rate. The analytical parameters with negative ion mode were performed as follows: source temperature $150{ }^{\circ} \mathrm{C}$, desolvation temperature $350{ }^{\circ} \mathrm{C}$, cone voltage $50 \mathrm{eV}$, capillary voltage $3 \mathrm{kV}$, cone gas flow 50 $\mathrm{L} / \mathrm{h}$, desolvation gas flow $600 \mathrm{~L} / \mathrm{h}$. The ion mass spectra were acquired between $\mathrm{m} / \mathrm{z} 50-1000$ and the peaks data were processed using the Bruker Daltonics Data Analysis 3.4 software. By comparing with the retention time of spectra and reported mass spectrum data with the literature on genus Ficus and family Moraceae, the bioactive compounds were identified. 


\section{$1 \quad$ Results and Discussion}

2 Impact of solvent on extraction process. Before using RSM, the impact of solvent type and

3 solvent to solid ratio were studied. Solvent selection is an important tool for the extraction of

4 plant metabolites. Generally, two polar solvents such as methanol (high polarity) and ethanol

5 (medium polarity), are used for the extraction processes when focusing on phenolic

6 compounds. For the extraction purposes, US Food and Drug Administration (UFDA)

7 recommended environment friend and food-grade non-toxic organic solvents and pure

8 methanol is more toxic than the pure ethanol ${ }^{31}$. In the present study, several of these solvents

9 were used alone or in combination with water. Our results suggested that the efficiency of

10 methanol was higher than single solvent ethanol, ethyl acetate and $n$-hexane, but lower than

11 the aqueous ethanol (75\%) to extract phenolic antioxidant compounds from the fruits of $F$.

12 auriculata as per the conditions of $10: 0.250(\mathrm{~mL} / \mathrm{g})$ solvent to solid ratio, $40{ }^{\circ} \mathrm{C}$ temperature

13 and 30 min extraction time (Figure 3). From our study, the extraction ability of the bioactive

14 phenolic compounds depends on the polarity of the solvent. In this study four solvents were

15 chosen based on the polarity index with different dielectric constant ( $\varepsilon$ ). Methanol is highly

16 polar solvent where ethanol is medium polar and ethyl acetate is low polar solvent. According

17 to the figure 3, n-hexane showed very low activity as it is a non-polar solvent with very low

18 dielectric constant $(\varepsilon=1.88)$. Therefore, due to the low toxicity and better extraction ability of aqueous ethanol, it was chosen as the master solvent for each of the next experimental runs for the determination of antioxidant activity and TPC from the fruits of $F$. auriculata. This agreed with several studies that also found that the combination of water with pure solvent is more effective than solvent alone for extracting phenolic antioxidant compounds ${ }^{32-35}$. So, the aqueous ethanol was the best solvent to extract polyphenols and the addition of water increased the polarity of the ethanol and the extraction potential in this case. 


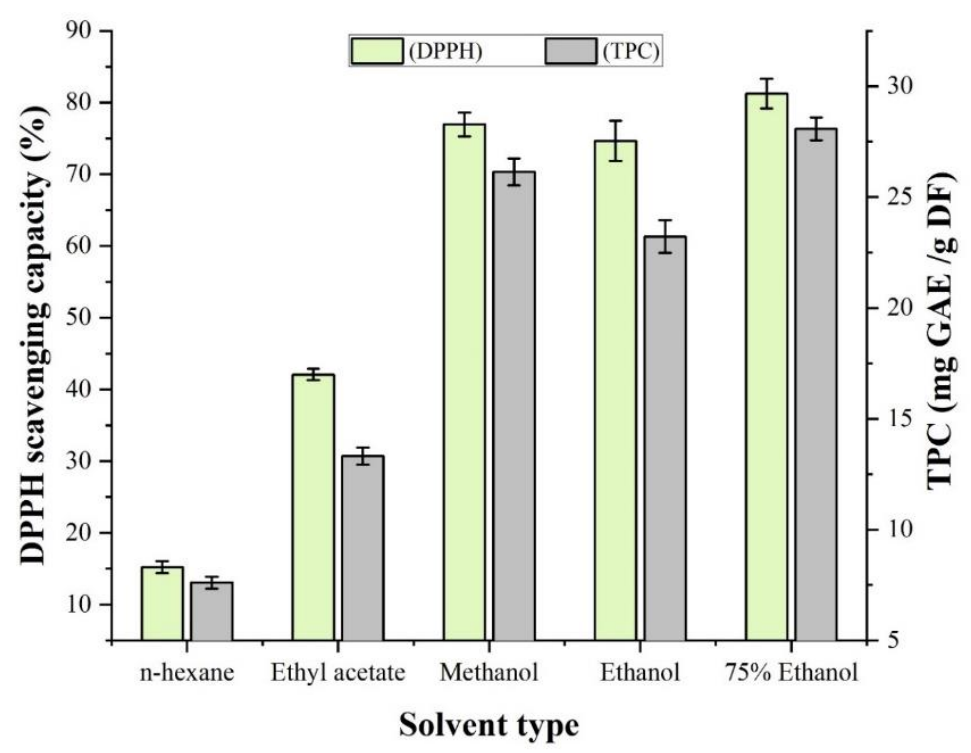

1

2 Figure 3. Effect of solvent on the antioxidant activity and TPC of fruits of Ficus auriculata. 3

4

13 requirement.

The influence of solvent to solid ratio on the extraction process from the fruits extract of F. auriculata was also studied with four ratio: 10/0.150, 10/0.250, 10/0.350 and 10/0.450 mL/g, over $75 \%$ of solvent, $30 \mathrm{~min}$ reaction time and $40{ }^{\circ} \mathrm{C}$ temperature. Figure 4 presents the outcomes. The antioxidant activities and TPC increased with the increased amount of solid 8 material in a fixed amount of solvent $(10 \mathrm{~mL})$, and it increased up to $0.250 \mathrm{mg}$ of solid. After that, the trend followed a declined efficiency. This is because, the speed of mass transfer depends on the ratio of solvent to solid and increasing ratio enable the distribution of 1 antioxidants into the extraction solvent till maximize the mass transfer. Therefore, the ratio of $210 / 0.250(\mathrm{~mL} / \mathrm{g})$ was chosen for each of the next experimental runs and to minimize the solvent 


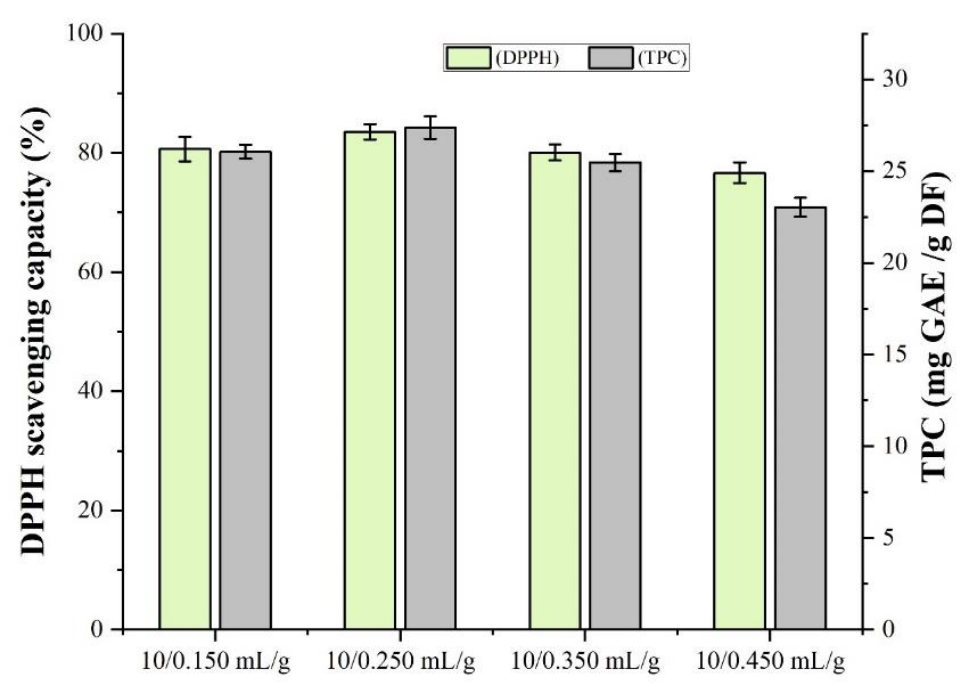

Solvent to solid ratio

2 Figure 4. Effect of solvent to solid ratio on the antioxidant and TPC of fruits of Ficus 3 auriculata extracted with $75 \%$ ethanol.

5 Fitting the RSM models. The results (antioxidant activity and TPC values) of the CCD design are shown in Table 2. Moreover, the response surface quadratic model was used to evaluate the extraction process to maximize the inhibition of DPPH and obtain the highest TPC from the fruit extracts of $F$. auriculata. Ethanol concentration $\left(\mathrm{X}_{1}\right)$, temperature $\left(\mathrm{X}_{2}\right)$ and time of extraction $\left(\mathrm{X}_{3}\right)$, were used as the independent variables which also commented before. The regression coefficient $\left(R^{2}\right)$ was checked to measure the degree of fitness ${ }^{36}$. When $R^{2}$ approaches unity, the model can significantly fit well with the predicted values ${ }^{37}$. The $\mathrm{R}^{2}$ value and ANOVA results of the response surface quadratic models for $F$. auriculata fruits extracts are compiled in Table 3 and Table 4, respectively. In the present study, $R^{2}$ values for antioxidant activity and TPC were 0.96 , for the quadratic model as well as 0.98 and 0.99 respectively for cubic model, but the design suggested quadratic model and aliased cubic model. The high values of $\mathrm{R}^{2}$ indicate that there is a good relationship between the predicted and experimental values for the models. The degree of precision of a model also can be checked by the coefficient of variations (C.V.). A high value of C.V. indicates the lower reliability of the experiment ${ }^{32}$. In this study, the C.V. values were $1.17 \%$ and $7.47 \%$ for antioxidant activity and TPC, respectively, which were low and indicates the executed experiments are highly reliable. 
1 Table 2. Experimental design using RSM with CCD for the antioxidant activity (\% of DPPH)

2 and total phenolic content (TPC)

\begin{tabular}{|c|c|c|c|c|c|}
\hline Run & $\begin{array}{c}\text { Ethanol } \\
\text { Conc. }(\%)\end{array}$ & $\begin{array}{l}\text { Temp } \\
\left({ }^{0} \mathrm{C}\right)\end{array}$ & Time (min) & $\begin{array}{l}\text { Antioxidant Activity } \\
\text { (\% of DPPH Inhibition) }\end{array}$ & $\begin{array}{c}\text { TPC } \\
\text { (mg GAE/g DL) }\end{array}$ \\
\hline & $\mathrm{X}_{1}$ & $\mathrm{X}_{2}$ & $\mathrm{X}_{3}$ & Experimental & Experimental \\
\hline 1 & 50 & 40 & 20 & 83.48 & 33.14 \\
\hline 2 & 7.95 & 40 & 20 & 77.23 & 13.21 \\
\hline 3 & 75 & 55 & 30 & 75.61 & 25.57 \\
\hline 4 & 75 & 55 & 10 & 77.77 & 19.03 \\
\hline 5 & 75 & 25 & 30 & 78.93 & 23.06 \\
\hline 6 & 92.04 & 40 & 20 & 81.87 & 17.89 \\
\hline 7 & 25 & 55 & 30 & 76.64 & 19.59 \\
\hline 8 & 50 & 40 & 20 & 83.73 & 33.18 \\
\hline 9 & 50 & 14.77 & 20 & 81.61 & 30.65 \\
\hline 10 & 25 & 25 & 30 & 77.41 & 16.35 \\
\hline 11 & 50 & 40 & 20 & 83.83 & 33.25 \\
\hline 12 & 25 & 55 & 10 & 77.41 & 18.78 \\
\hline 13 & 25 & 25 & 10 & 78.28 & 17.40 \\
\hline 14 & 50 & 40 & 3.18 & 75.87 & 13.85 \\
\hline 15 & 75 & 25 & 10 & 79.74 & 18.68 \\
\hline 16 & 50 & 40 & 36.81 & 74.27 & 25.80 \\
\hline 17 & 50 & 40 & 20 & 84.54 & 33.41 \\
\hline 18 & 50 & 65.22 & 20 & 81.05 & 27.07 \\
\hline 19 & 50 & 40 & 20 & 84.92 & 34.03 \\
\hline 20 & 50 & 40 & 20 & 84.70 & 33.92 \\
\hline
\end{tabular}

3

4 Table 3. Adequacy of the model tested for the responses

\begin{tabular}{|c|c|c|c|c|c|c|c|c|c|c|}
\hline \multicolumn{6}{|c|}{$\begin{array}{c}\text { Antioxidant activity } \\
\text { (\% of DPPH Inhibition) }\end{array}$} & \multicolumn{5}{|c|}{$\begin{array}{l}\text { Total phenolic content } \\
\text { (mg GAE/g DF) }\end{array}$} \\
\hline Source & Std. Dev. & $\mathrm{R}^{2}$ & $\mathbf{R}_{\text {Adj }}^{2}$ & $\mathrm{R}^{2}$ Pre & C.V. & Std. Dev. & $\mathrm{R}^{2}$ & $\mathrm{R}_{\mathrm{Adj}}^{2}$ & $\mathrm{R}_{\text {Pre }}^{2}$ & C.V. \\
\hline Linear & 3.61 & 0.07 & -0.10 & -0.35 & & 7.71 & 0.09 & -0.06 & -0.31 & \\
\hline $2 \mathrm{FI}$ & 3.99 & 0.07 & -0.34 & -1.46 & & 8.47 & 0.11 & -0.29 & -1.31 & \\
\hline Quadratic & 0.93 & 0.96 & 0.92 & 0.75 & 1.17 & 1.82 & 0.96 & 0.94 & 0.76 & 7.47 \\
\hline Cubic & 0.69 & 0.98 & 0.95 & -0.10 & & 0.72 & 0.99 & 0.99 & 0.49 & \\
\hline
\end{tabular}


1 Table 4. Analysis of variance (ANOVA) for response surface quadratic model

\begin{tabular}{|c|c|c|c|c|c|c|c|c|c|c|}
\hline \multirow[b]{2}{*}{ Source } & \multicolumn{6}{|c|}{ Antioxidant activity } & \multicolumn{4}{|c|}{ Total phenolic content } \\
\hline & $\begin{array}{l}\text { Sum of } \\
\text { Squares }\end{array}$ & $\mathrm{DF}$ & $\begin{array}{l}\text { Mean } \\
\text { Square }\end{array}$ & $F$ Value & $P$ Value & $\begin{array}{l}\text { Sum of } \\
\text { Squares }\end{array}$ & DF & $\begin{array}{l}\text { Mean } \\
\text { Square }\end{array}$ & $F$ Value & $P$ Value \\
\hline Model & 220.05 & 9 & 24.45 & 29.46 & $<0.0001$ & 1023.42 & 9 & 113.71 & 34.23 & $<0.0001$ \\
\hline $\mathrm{X}_{1}$ & 7.51 & 1 & 7.50 & 9.04 & 0.0132 & 35.75 & 1 & 35.74 & 10.76 & 0.0083 \\
\hline$X_{2}$ & 4.53 & 1 & 4.53 & 5.46 & 0.0416 & 0.16 & 1 & 0.15 & 0.04 & 0.8324 \\
\hline $\mathrm{X}_{3}$ & 3.89 & 1 & 3.88 & 4.68 & 0.0557 & 69.35 & 1 & 69.35 & 20.88 & 0.0010 \\
\hline $\mathrm{X}_{1}^{2}$ & 46.24 & 1 & 46.24 & 55.72 & $<0.0001$ & 613.87 & 1 & 613.87 & 184.8 & $<0.0001$ \\
\hline $\mathrm{X}_{2}^{2}$ & 19.46 & 1 & 19.45 & 23.45 & 0.0007 & 47.70 & 1 & 47.70 & 14.36 & 0.0035 \\
\hline $\mathrm{X}_{3}^{2}$ & 164.07 & 1 & 164.07 & 197.73 & $<0.0001$ & 362.35 & 1 & 362.35 & 109.1 & $<0.0001$ \\
\hline $\mathrm{X}_{1} \mathrm{X}_{2}$ & 1.67 & 1 & 1.67 & 2.01 & 0.1861 & 0.38 & 1 & 0.38 & 0.11 & 0.7419 \\
\hline $\mathrm{X}_{1} \mathrm{X}_{3}$ & 0.22 & 1 & 0.22 & 0.27 & 0.6139 & 15.57 & 1 & 15.56 & 4.68 & 0.0556 \\
\hline $\mathrm{X}_{2} \mathrm{X}_{3}$ & 0.20 & 1 & 0.19 & 0.23 & 0.6373 & 2.01 & 1 & 2.01 & 0.60 & 0.4545 \\
\hline Residual & 8.30 & 10 & 0.83 & & & 33.21 & 10 & 3.32 & & \\
\hline Lack of Fit & 6.99 & 5 & 1.39 & 5.33 & 0.0449 & 32.45 & 5 & 6.49 & 42.71 & 0.0004 \\
\hline Pure Error & 1.31 & 5 & 0.26 & & & 0.76 & 5 & 0.15 & & \\
\hline Cor Total & 228.35 & 19 & & & & 1056.64 & 19 & & & \\
\hline
\end{tabular}

The probability factor $(P$-value $)$ is another important value to evaluate the significance

4 of independent variables. A lower $P$-value is highly recommended for significance ${ }^{38}$. In the

5 present study, the model was significant due to the value of $P$ was less than 0.05 . According to

6 Table 4, two linear coefficients such as $X_{1}$ and $X_{2}$ and three quadratic term coefficients such as

$7 \mathrm{X}_{1}^{2}, \mathrm{X}_{2}^{2}$ and $\mathrm{X}_{3}^{2}$ were significant $(P<0.05)$ for the response of antioxidant activities. In

8 contrast, two linear coefficients $\left(\mathrm{X}_{1}\right.$ and $\left.\mathrm{X}_{3}\right)$ and all the quadratic term coefficients $\left(\mathrm{X}_{1}{ }^{2}, \mathrm{X}_{2}{ }^{2}\right.$

9 and $\mathrm{X}_{3}{ }^{2}$ ) were significant for the response of TPC. The other terms of coefficients were

10 insignificant due to the $P$-value was $>0.05$. Furthermore, the model $F$-value for antioxidant

11 activity and TPC were 29.46 and 34.23, respectively (Table 4). The high $F$-values further

12 confirmed the models significant within the studied range of process conditions. Moreover, the

13 lack of fit for this model also significant (P-value <0.05). Therefore, all the results proved that

14 the model fitness was adequate and both models were fully applicable. Figure 5 represents the

15 Predicted vs Actual values for Antioxidant activity and TPC. The perfect fit line Predicted =

16 Actual values with a high degree of correlation with best fit line equation $\mathrm{y}=\mathrm{mx}+\mathrm{c}$ indicates

17 the best accuracy of the current model. 

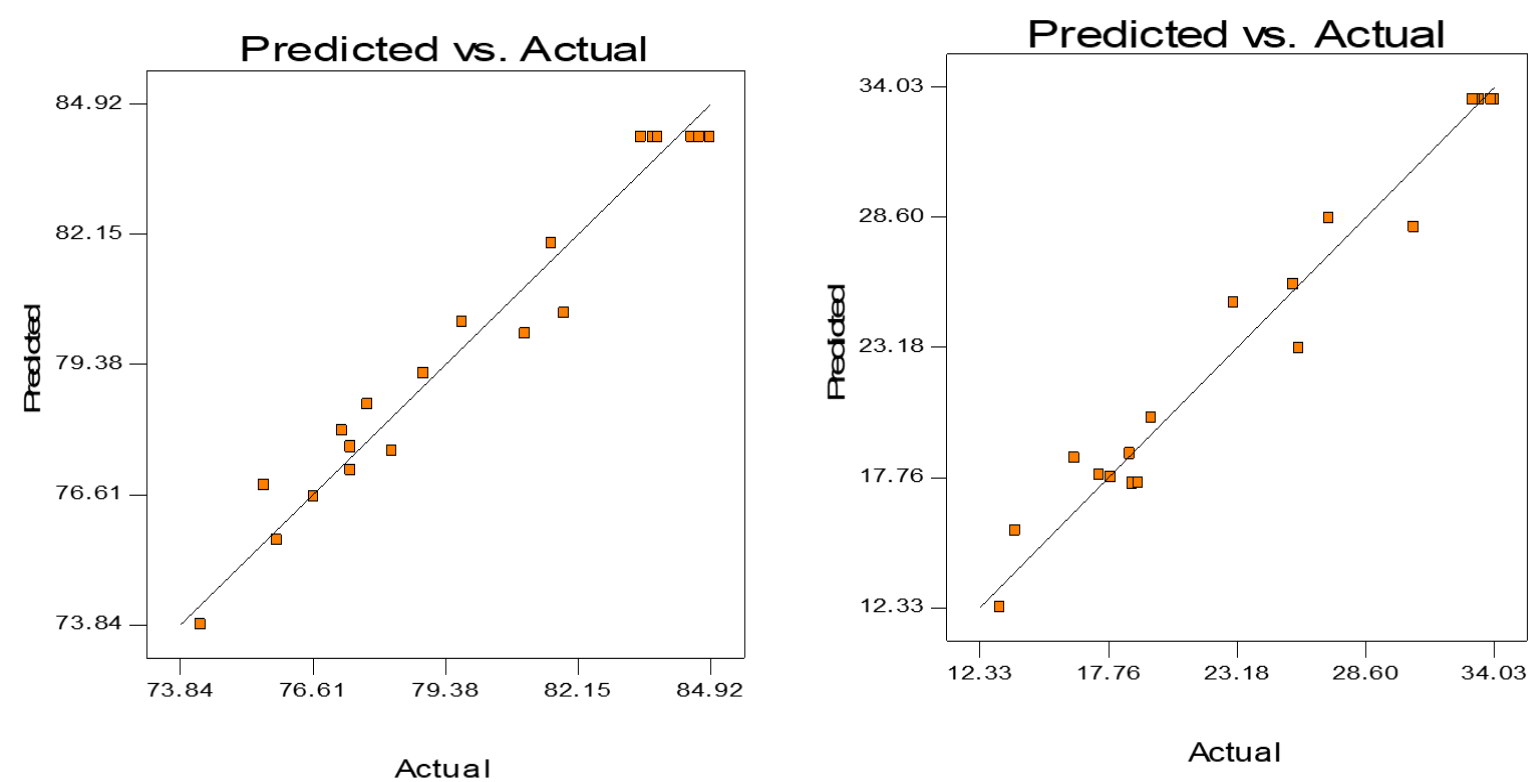

2 Figure 5. Predicted vs Actual values curve for Antioxidant activity and TPC of F. auriculata

3 fruit extract

4

5 Impact of extraction parameters on DPPH assay. The effects of solvent, extraction

6 temperature and sonication time on the DPPH assay of fruit extracts of $F$. auriculata as well as

7 their interactions are shown in Table 2 and Figure 6. Equation (4) displays the correlation

8 between independent variables for the DPPH radical scavenging activity of $F$. auriculata fruits

9 extracts.

10

$11 \mathrm{Y}_{1}(\%$ of $\mathrm{DPPH})=84.21+0.74 \mathrm{X}_{1}-0.57 \mathrm{X}_{2}-0.53 \mathrm{X}_{3}-1.76 \mathrm{X}_{1}^{2}-1.14 \mathrm{X}_{2}^{2}-3.35 \mathrm{X}_{3}^{2}-0.45$

$$
\mathrm{X}_{1} \mathrm{X}_{2}-0.17 \mathrm{X}_{1} \mathrm{X}_{3}-0.15 \mathrm{X}_{2} \mathrm{X}_{3}
$$

13

14 where $\mathrm{Y}_{1}$ represents the DPPH radical scavenging activity in fruit extracts of $F$.

15 auriculata. $\mathrm{X}_{1}, \mathrm{X}_{2}$, and $\mathrm{X}_{3}$ represents the solvent concentration $(\%)$, temperature $\left({ }^{\circ} \mathrm{C}\right)$ and time 16 (min), respectively. 


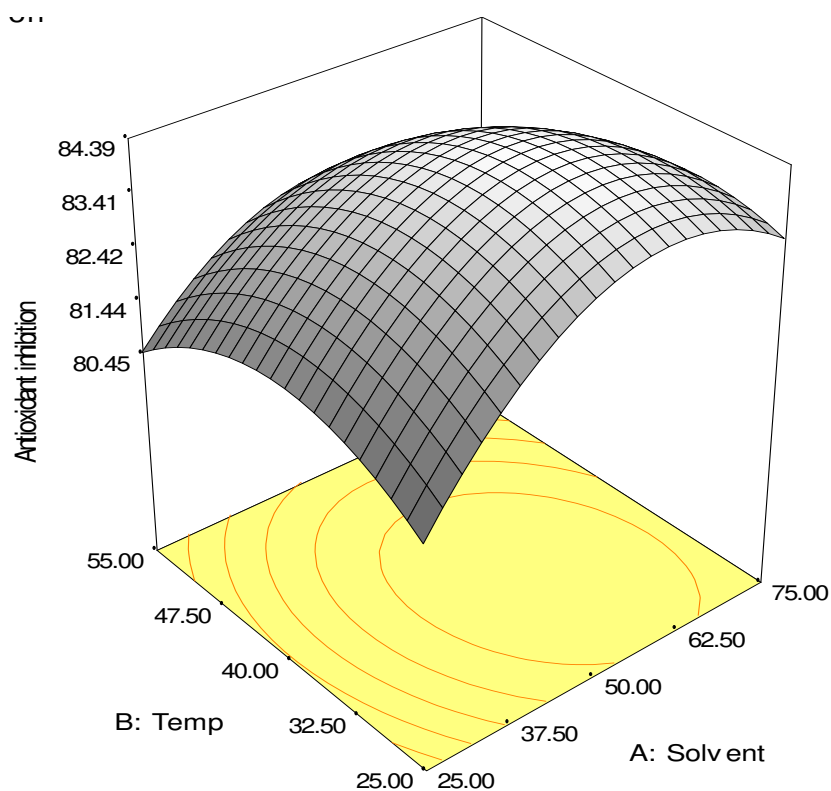

(a)

3

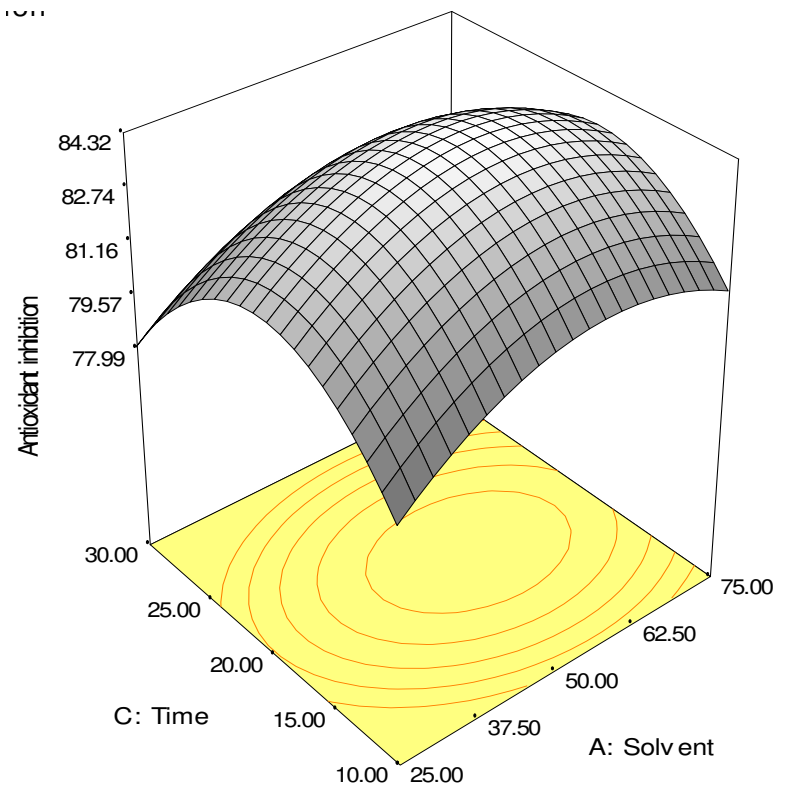

(b) 
3 Figure 6. Response surface plots showing the effects of extraction parameters on the DPPH of

(c)

4 the extracts from fruits of $F$. auriculata. (a) The constant ultrasonic time (20 min), (b) the

constant temperature $\left(40{ }^{\circ} \mathrm{C}\right)$, and (c) the constant ethanol concentration $(50 \%)$.

We selected the DPPH assay since it is a broadly used and reliable antioxidant determination method compared to other assays ${ }^{39}$. In this process, DPPH solution reduced to non-radical DPPH-H in the presence of hydrogen-donating antioxidants. The antioxidant compound containing crude fruit extract of $F$. auriculata fruits reduced the stable purple colour 1 to yellow-coloured diphenylpicryl-hydrazine. The experimental and predicted values of DPPH 2 assay with various extraction conditions are shown in Table 2. The variables studied here, the 3 concentration of ethanol, sonication temperature and sonication time, showed the effects on the 4 antioxidant activity of fruit extract of this plant. At constant sonication time (20 min), the 5 ethanol concentration and temperature effect on DPPH inhibition of $F$. auriculata fruit extract 6 seemed as light-saddled shapes (Figure 6a). The ethanol concentration $(P<0.0001)$ and the 17 temperature were the main significant extraction parameters for antioxidant activity. The 8 effects of sonication time were not statistically significant $(P>0.05)$, but their quadratic terms 9 were significant as commented before. The DPPH inhibition increases with the growth of 0 ethanol concentration from $7.95 \%$ to $52.50 \%$, and thereafter it followed the declining trend at 1 the higher solvent concentration of $92.04 \%$.

22 The similar trend also found for ultrasound irradiation time for this study (Figure 6b). 23 The DPPH radical scavenging activities increased from 3 to $22 \mathrm{~min}$ and followed by a

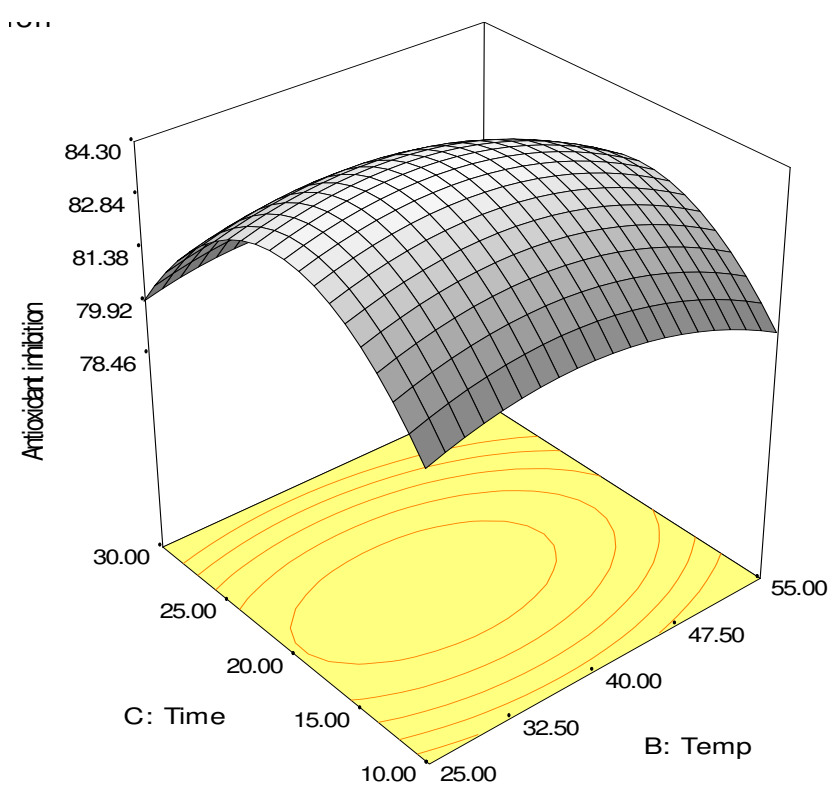


1 decreasing trend at longer ultrasound irradiation time. Maximum $84.03 \%$ of inhibition was

obtained at $22 \mathrm{~min}$. When the ethanol concentration and sonication time were kept constant, the antioxidant activity of the extracts enlarged to a value with the temperature and then started to decrease (Figure 6c). These studies evidently exhibit that the change of ethanol concentration and temperature, change the activity of DPPH positively in the medium region, and thereafter follow the negative trend for any range of extraction time.

Concerning other studies, similar DPPH radical scavenging antioxidant response plots were also reported by Shahinuzzaman et al. for F. carica latex ${ }^{40}$, Yang et al. (2008) earlier for longan fruit polysaccharides ${ }^{39}$, Ilaiyaraja et al. (2015) for fruit extract of Feronia limonia ${ }^{41}$ and Liyana-Parthirana \& Shahidi (2005) for wheat extracts ${ }^{21}$. In ultrasound assisted extraction, the DPPH radical scavenging activities of the fruit extract of $F$. auriculata were higher than those of Shirzad and co-worker reported leaves of Olea europaea $(78.98 \%)^{42}$. Li et al. (2016) reported leaves extract of $P$. frutescens $(73.66 \%)^{25}$; Ilaiyaraja and co-workers reported fruit extract of $F$. limonia $(83.8 \%)^{41}$, Tabaraki and Nateghi $(2011)$ reported rice bran $(52.83 \%)^{22}$. However, the maximum antioxidant activity value obtained for $F$. auriculata was lower than that reported for olive leaves $(95.56 \%)^{43}$.

\section{Impact of extraction parameters on TPC.}

The effects of the extraction parameters, on the TPC of fruit extracts of $F$. auriculata under UAE is presents in Table 2. The effect of ethanol concentration and sonication time was decidedly significant as well as the effects of temperature was not statistically significant on the extraction of phenolic compounds. However, multiple regression analysis indicated that the quadratic terms $\left(\mathrm{X}_{1}^{2}, \mathrm{X}_{2}^{2}\right.$ and $\left.\mathrm{X}_{3}^{2}\right)$ were highly significant $(p<0.0001$ ) for the extraction of TPC and is revealed in Table 3 , as for the antioxidant activity. So, consistent with the experimental values, the model made the second-order polynomial equations to exhibit the correlation between ethanol concentration, temperature and time for the TPC $\left(\mathrm{Y}_{2}\right)$, is represented in equations 5:

$$
\mathrm{Y}_{2}(\mathrm{mg} \mathrm{GAE} / \mathrm{g} \mathrm{DL})=33.51+1.61 \mathrm{X}_{1}+0.11 \mathrm{X}_{2}+2.25 \mathrm{X}_{3}-6.52 \mathrm{X}_{1}^{2}-1.82 \mathrm{X}_{2}^{2}-5.01 \mathrm{X}_{3}^{2}
$$

$$
-0.22 \mathrm{X}_{1} \mathrm{X}_{2}+1.39 \mathrm{X}_{1} \mathrm{X}_{3}+0.50 \mathrm{X}_{2} \mathrm{X}_{3}
$$

A $3 \mathrm{D}$ response surface plots were established to obtain the optimum extraction parameters for TPC based on Eq. (5). When sonication time was kept constant (20 min), the effect of solvent and temperature on TPC seemed as a curved shape (Figure 7a). The TPCs linearly increases with uplifting the ethanol concentration until it reaches a highest limit and then reduced. The highest recovery of phenolics was gained at a solvent concentration between 
$1 \quad 45-55 \%$ and temperature between $38-43{ }^{\circ} \mathrm{C}$. TPC gradually mounted up and attained a 2 maximum content ( $\sim 33.88 \mathrm{mg}$ TE /g DL) and followed by a sharp decrease afterwards. In this 3 study, the TPC was meaningfully affected by the varying concentration of ethanol and the 4 extraction of phenolic compounds was higher at $52.5 \%$ of ethanol thereafter it decreased at the 5 higher concentration of ethanol $(75-92.04 \%)$. These results are interesting to minimize the 6 global process cost due to the use of ethanol as a solvent.

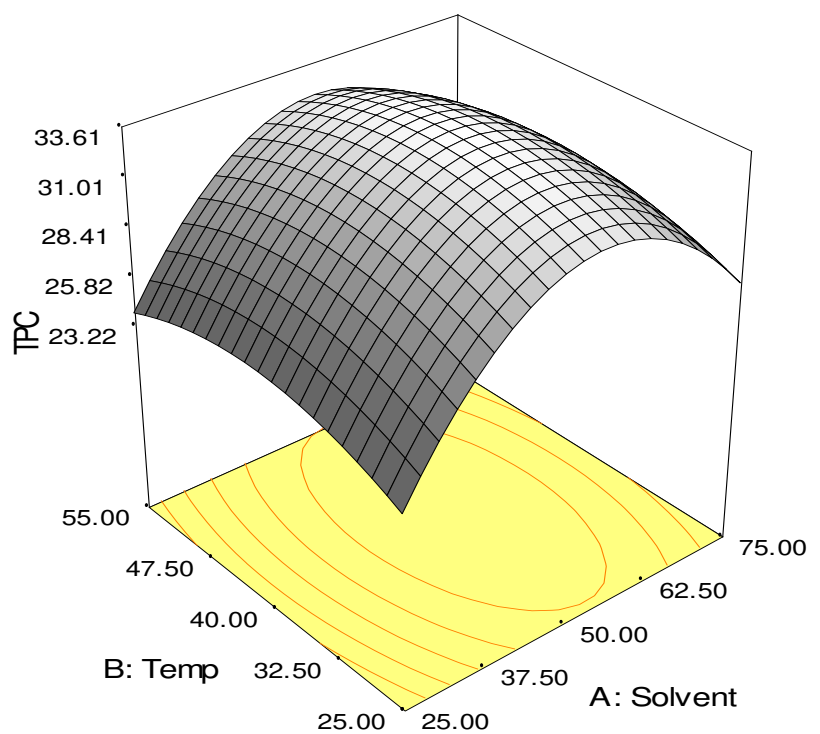

(a)

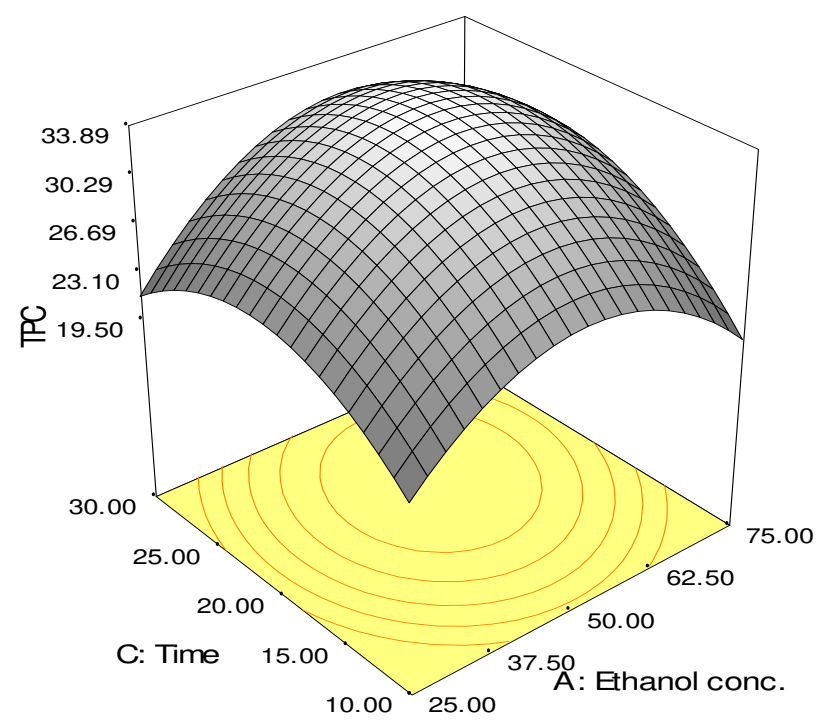




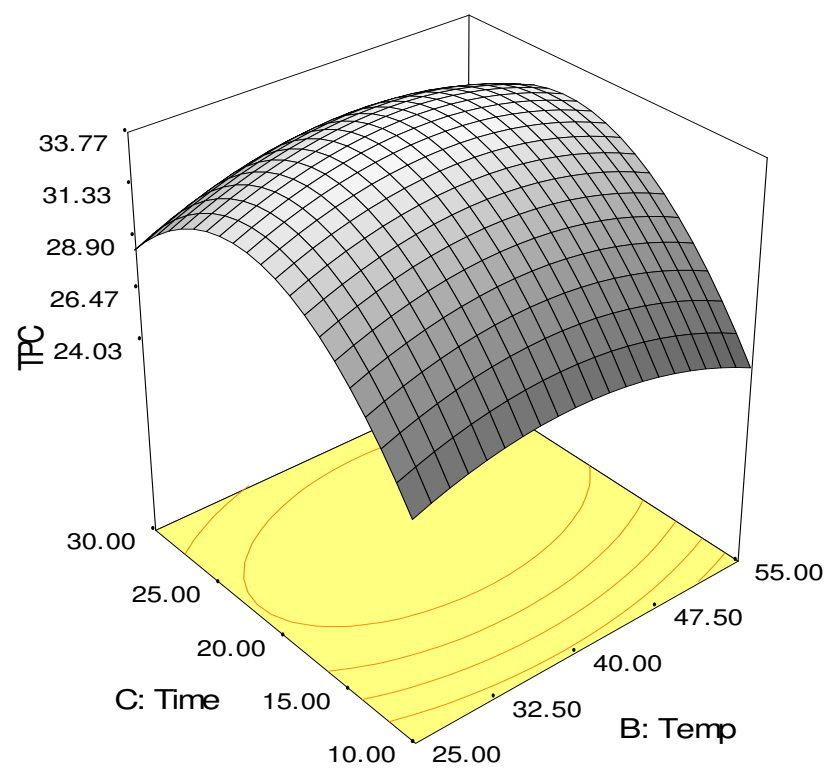

(c)

Figure 7. Response surface plots showing effects of ethanol concentration, temperature and sonication time on total phenolic contents of the extracts from fruits of $F$. auriculata. (a) The constant ultrasonic time (20 min), (b) the constant extraction temperature $\left(40{ }^{\circ} \mathrm{C}\right)$, and (c) the constant ethanol concentration (50\%).

At constant temperature $\left(40^{\circ} \mathrm{C}\right)$, the relationship of sonication time and concentration of ethanol on TPC is exposed in Figure $7 \mathrm{~b}$. The concentration of ethanol revealed a prominent impact on TPC in a quadratic manner (Table 3). The TPC increases with increasing the ethanol concentration up to $52.5 \%$ and additional concentration of ethanol reduced the TPC, probably for the polarity change of the solvent mix.

To enhance the yield of phenolic compounds, temperature plays a vital role to soft the plant tissues, increase the solubility and dispersion coefficient of the constituents ${ }^{41}$. In this case, lower recovery of TPC obtained at the higher temperature $\left(65^{\circ} \mathrm{C}\right)$, and $52.5 \%$ of ethanol agrees well. The results found from this study are more favourable compared to previous studies which presented equivalent or higher for the fruit extract of $F$. limonia ${ }^{41}$, leaves extract of $P$. frutescens $^{25}$, rice bran ${ }^{22}$, extracts of grape cane ${ }^{44}$, peels extract of Mangifera pajang ${ }^{45}$ etc.

9 At constant ethanol concentration, the effect of temperature and sonication time on the yield of TPC is shown in Figure 7c. TPC of fruit extracts of $F$. auriculata increased sharply with increasing temperature up to $40{ }^{\circ} \mathrm{C}$ and thereafter decreased slightly. This phenomenon observed in our study at moderate temperature due to it could soften the plant tissue, weaken the integrity of the cell wall, hydrolyze the bonds between phenol-polysaccharide or phenol- 
1 protein and enrich the solubility of phenolics, thus more phenolic compounds would pass to

2 the extraction solvent ${ }^{46}$.

3

4 Validation of the optimal extraction conditions. The optimum operating conditions were

5 performed in DOE software based on each experimental run and combination of the two

6 responses. The goal of this study was to obtain the highest antioxidant activity and yield of

7 total phenolic content from the fruit extracts of $F$. auriculata within the range of extraction

8 parameters. To optimise the extraction parameters of antioxidant activity, an ethanol

9 concentration of $52.5 \%(\mathrm{v} / \mathrm{v})$, the temperature of $40{ }^{\circ} \mathrm{C}$, and ultrasound irradiation time of 22

10 min were chosen. The highest TPC also found at the same optimum extraction parameters.

11 These optimum conditions gave the highest response value of $84.03 \%$ for DPPH assay and

$1233.88 \mathrm{mg} \mathrm{GAE} / \mathrm{g}$ DF for TPC, which was forecasted from the model (Table 5).

14 Table 5. Estimated optimum conditions for DPPH, ABTS and TPC

\begin{tabular}{cccccc}
\hline \multirow{2}{*}{ Response variables } & \multicolumn{2}{c}{ Optimum UAE condition } & \multicolumn{2}{c}{ Maximum values } \\
\cline { 2 - 6 } & Ethanol (\%) & Temp $\left({ }^{\circ} \mathrm{C}\right)$ & Time $($ min) & Experimental & Predicted \\
\hline DPPH (\%) & 52.5 & 40 & 22 & $85.20 \pm 0.96$ & 84.03 \\
ABTS (\%) & 52.5 & 40 & 22 & $99.12 \pm 1.25$ & - \\
TPC (mg GAE/ g FW) & 52.5 & 40 & 22 & $33.25 \pm 0.94$ & 33.88 \\
\hline
\end{tabular}

15

The validation of the model was also checked at the predicted conditions. The optimal conditions were also tested by using one more radical scavenging assay, i.e. ABTS assay. The outcomes of the experiments showed the following values: $85.20 \pm 0.96 \%$ for DPPH, $99.12 \pm$ $1.25 \%$ for ABTS and $33.25 \pm 0.94 \mathrm{mg} \mathrm{GAE} / \mathrm{g}$ DF for the TPC, which were reliable with the predictive value. The strong relationship between the predicted and experimental values confirmed that the model is correct and consistent in finding the optimal conditions for antioxidants activity and TPC from the fruit extracts of $F$. auriculata.

Characterization of bioactive compounds at optimized extract using LC-ESI-MS. The characterization of phenolic compounds was performed by LC-ESI-MS in the negative ionization mode. For that, the most active extract was studied in depth (Figure 8): fruit of $F$. auriculata extracted through the ultrasonication extraction at the optimised extraction process. The retention time (RT), experimental $\mathrm{m} / \mathrm{z}$ of negative molecular ions ([M-H] $]^{-}$, in-source 
1 fragments ${ }^{47}$, and the proposed compounds are shown in Table 6 . The tentative compounds were 2 compared with the reported literature and databases. A total of 18 bioactive compounds were 3 characterized in F. auriculata for first time so far as we know, but few of them were reported 4 in other species. In this way, the preliminary structure of derivatives of Caffeoylquinic acid 5 (compounds 2-4), linolenic acid (compound 16) were proposed on the basis of their $\mathrm{m} / \mathrm{z}$ and 6 fragments. For example, the ion $\mathrm{m} / \mathrm{z} 353$ may indicate the presence of a caffeoylquinic moiety 7 in compounds 2, 3 and 4. The unique hydroxycinnamic acid found in the extract was 8 caffeoylquinic acid (compound 2-4), whose occurrence were previously reported in $F$. carica 9 fruits ${ }^{48-50}$. Flavanols were represented by A-type trimer (compounds 8) $(\mathrm{m} / \mathrm{z} \mathrm{863)}$ as also described Vallejo and co-workers (2012) in F. carica fruits $^{50}$. Their fragmentation patterns 11 agreed with previous studies by observing the monomer unit $(\mathrm{m} / \mathrm{z} 289)$, dimer $(\mathrm{m} / \mathrm{z}, 577)$, a 12 fragment ion derived from a retro-Diels-Alder fission at $\mathrm{m} / \mathrm{z}, 425$ and its subsequent loss of 13 water $(\mathrm{m} / \mathrm{z} 407)$ depending on the compound $\mathrm{d}^{51,52}$. Isoflavones consisted of three compounds such as Trihydroxy-octadecadienoic acid, Trihydroxy octadecanoic acid and Hydroxyoctadecatrienoic acid (compounds 10,11,13). Most of them have been reported in several Ficus species, including F. carica, F. tikoua, F. mucuso, and F. septica ${ }^{48,49,53-56}$.

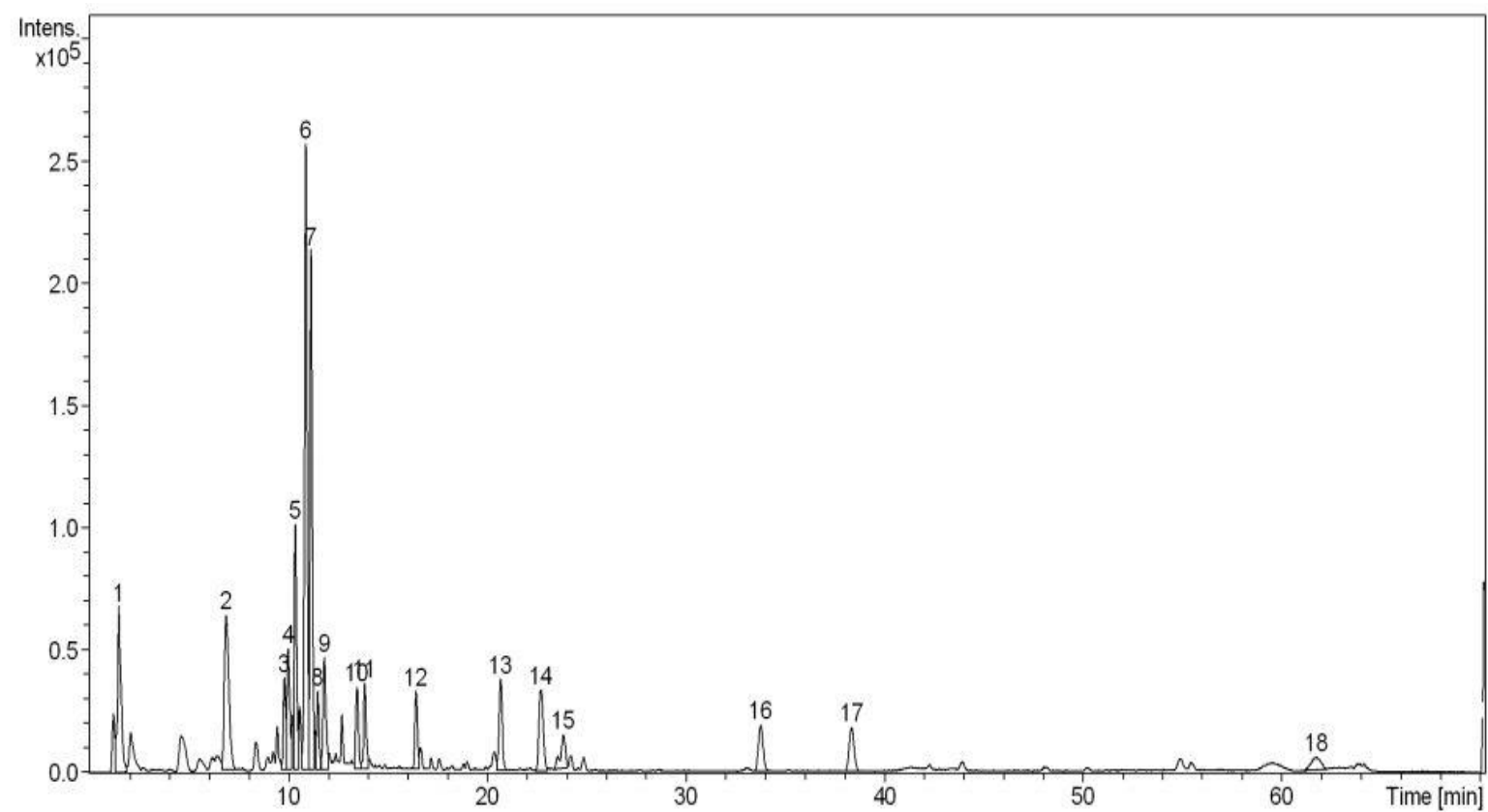

19 Figure 8. LC-MS fingerprinting analysis of fruits of $F$. auriculata analysed in the negative 20 ionization mode. 
1 Table 6. Tentative identification of chemical constituents of $F$. auriculata fruit by HPLC-ESI $-\mathrm{MS} / \mathrm{MS}$

\begin{tabular}{lccccc}
\hline $\begin{array}{c}\text { Peak } \\
\text { No. }\end{array}$ & RT & MW & {$[\text { M-H }]^{-}$} & MS & Identified compounds \\
\hline 1 & 1.49 & 342 & 341 & 191 & \\
2 & 6.9 & 354 & 353 & 191 & Galloylquinic acid \\
3 & 9.81 & 354 & 353 & 191 & 3-O- caffeoylquinic acid \\
4 & 10.00 & 354 & 353 & 191,179 & 4- $O$ - caffeoylquinic acid \\
5 & 10.37 & 866 & 865 & 577,289 & 5-O- caffeoylquinic acid \\
6 & 10.89 & 626 & 625 & 367,173 & 4-O- feruloylquinic acid derivatives \\
7 & 11.16 & 610 & 609 & 577,289 & Methoxyl-epicatchin dimer \\
8 & 11.49 & 864 & 863 & 577,289 & Epicatchin-trimer (A-type) \\
9 & 11.83 & 410 & 409 & 277,173 & Unidentified \\
10 & 13.47 & 328 & 327 & 211,171 & Trihydroxy-octadecadienoic acid \\
11 & 13.85 & 330 & 329 & 211 & Trihydroxy octadecanoic acid \\
12 & 16.43 & 488 & 487 & 305,173 & Gallocatchin- $O$-hexoside \\
13 & 20.68 & 294 & 293 & 275 & Hydroxy-octadecatrienoic acid \\
14 & 22.70 & 296 & 295 & 277,171 & Xanthone derivatives \\
15 & 23.83 & 472 & 471 & 295,173 & 3- methyl epigallocatechin gallate \\
16 & 33.75 & 278 & 277 & 173 & Linolenic acid \\
17 & 38.33 & 280 & 279 & 173 & Linoleic acid \\
18 & 61.69 & 572 & 571 & 173,147 & Unidentified \\
\hline & & & & &
\end{tabular}

\section{Conclusions}

$9 \mathrm{UAE}$ is an environmentally friendly, simple, and economical extraction process for the 10 extraction of antioxidants from the fruits of $F$. auriculata. The correlation coefficient of this 11 model $\left(\mathrm{R}^{2}=0.98\right.$ for antioxidant activity and $\mathrm{R}^{2}=0.99$ for total phenolic content, $\left.P<0.0001\right)$

12 was high and suggested that a second-order polynomial model should be used. The highest 13 antioxidant activity $(85.20 \pm 0.96 \%$ for $\mathrm{DPPH})$ were obtained at optimum ethanol 
1 concentration of $52.50 \%(\mathrm{v} / \mathrm{v})$, a temperature of $40{ }^{\circ} \mathrm{C}$, and ultrasound irradiation time of 22 2 min. Under these conditions, the ABTS scavenging activity was $99.12 \pm 1.25 \%$. Moreover, the 3 highest yield of total phenolic contents $(33.25 \pm 0.94 \mathrm{mg} \mathrm{GAE} / \mathrm{g}$ DF) was obtained at the same

4 extraction parameters. The predicted and experimental data were almost similar. The profiling 5 of phenolic compounds of the optimized extract by LC-ESI-MS revealed the existence of 6 phenolic acids, flavanols, and isoflavones. These results supply valuable information to the 7 industry for the extraction of bioactive compounds from the optimized fruit extract.

9 Acknowledgements. The authors would like to thank Universiti Kebangsaan Malaysia for its 10 financial support to this research work under the grant DIP- 2018-007.

12 Conflicts of interest. The authors declare no competing financial interest.

\section{References}

151 Huang, D., Ou, B. \& Prior, R. L. The chemistry behind antioxidant capacity assays. Journal of agricultural and food chemistry 53, 1841-1856 (2005).

172 Yoshihara, D., Fujiwara, N. \& Suzuki, K. Antioxidants: Benefits and risks for longterm health.

Maturitas

67, 103-107, doi:http://dx.doi.org/10.1016/j.maturitas.2010.05.001 (2010).

3 Chatha, S. A. S., Hussain, A. I., Bajwa, J.-U.-R. \& Sagir, M. Antioxidant activity of different solvent extracts of rice bran at accelerated storage of sunflower oil. Journal of Food Lipids 13, 424-433, doi:10.1111/j.1745-4522.2006.00068.x (2006). Huxel, A. (MacMillan Press, 1992). Thingbaijam, R., Dutta, B. \& Paul, S. Phytochemical Screening and Antibacterial Studies of the Leaf Extract of Eurya japonica Thunb. and Ficus auriculata Lour. JOURNAL OF PURE AND APPLIED MICROBIOLOGY 5, 909-916 (2011).

518-521 (2012)

307 Gaire, B. P. et al. Phytochemical screening and analysis of antibacterial and antioxidant activity of Ficus auriculata (Lour.) stem bark. Pharmacognosy journal 3, 49-55 (2011). El-Fishawy, A., Zayed, R. \& Afifi, S. Phytochemical and pharmacological studies of Ficus auriculata Lour. Journal of Natural Products 4, 184-195 (2011). 
19 Akhtar, P., Yaakob, Z., Ahmed, Y. \& Shahinuzzaman, M. Ficus species good sources of natural antioxidant drugs. Turk J. Pharm. Sci (2019).

0 Hlail, S. H., Ahmad, W. J. W. \& Abdullah, A. Variations in antioxidant content in leaves and fruits of Ficus fistulosa. AIP Conference Proceedings 1614, 619-623, doi:10.1063/1.4895274 (2014).

11 Japón-Luján, R., Luque-Rodríguez, J. M. \& Luque de Castro, M. D. Dynamic ultrasound-assisted extraction of oleuropein and related biophenols from olive leaves. $\begin{array}{lllll}\text { Journal of } & \text { Chromatography }\end{array}$ doi:http://dx.doi.org/10.1016/j.chroma.2005.12.106 (2006).

12 Dahmoune, F., Nayak, B., Moussi, K., Remini, H. \& Madani, K. Optimization of microwave-assisted extraction of polyphenols from Myrtus communis L. leaves. Food Chemistry 166, 585-595, doi:http://dx.doi.org/10.1016/j.foodchem.2014.06.066 (2015).

13 Ranic, M. et al. Optimization of microwave-assisted extraction of natural antioxidants from spent espresso coffee grounds by response surface methodology. Journal of Cleaner Production 80, 69-79, doi:http://dx.doi.org/10.1016/j.jclepro.2014.05.060 (2014).

4 Ghafoor, K., Park, J. \& Choi, Y.-H. Optimization of supercritical fluid extraction of bioactive compounds from grape (Vitis labrusca B.) peel by using response surface methodology. Innovative Food Science \& Emerging Technologies 11, 485-490, doi:http://dx.doi.org/10.1016/j.ifset.2010.01.013 (2010).

15 Maran, J. P., Manikandan, S., Priya, B. \& Gurumoorthi, P. Box-Behnken design based multi-response analysis and optimization of supercritical carbon dioxide extraction of bioactive flavonoid compounds from tea (Camellia sinensis L.) leaves. Journal of Food Science and Technology 52, 92-104, doi:10.1007/s13197-013-0985-z (2015).

16 Chemat, F., Tomao, V. \& Virot, M. Ultrasound-assisted extraction in food analysis. Handbook of food analysis instruments, 85-103 (2008).

17 Toma, M., Vinatoru, M., Paniwnyk, L. \& Mason, T. J. Investigation of the effects of ultrasound on vegetal tissues during solvent extraction. Ultrasonics Sonochemistry $\mathbf{8}$, 137-142, doi:http://dx.doi.org/10.1016/S1350-4177(00)00033-X (2001).

8 Vinatoru, M. An overview of the ultrasonically assisted extraction of bioactive principles from herbs. Ultrasonics Sonochemistry 8, 303-313, doi:http://dx.doi.org/10.1016/S1350-4177(01)00071-2 (2001). 
119 Pan, Z., Qu, W., Ma, H., Atungulu, G. G. \& McHugh, T. H. Continuous and pulsed ultrasound-assisted extractions of antioxidants from pomegranate peel. Ultrasonics sonochemistry 18, 1249-1257 (2011).

20 Akhtar, P., Yaakob, Z., Ahmed, Y., Shahinuzzaman, M. \& Mar Contreras, M. Potential of Leaves of Eighteen Cultivars of Ficus carica as Antioxidants and Profiling of Phenolic Compounds as an Active Molecules. Iranian Journal of Pharmaceutical Sciences 15, 41-60 (2019).

21 Liyana-Pathirana, C. \& Shahidi, F. Optimization of extraction of phenolic compounds from wheat using response surface methodology. Food Chemistry 93, 47-56, doi:http://dx.doi.org/10.1016/j.foodchem.2004.08.050 (2005).

22 Tabaraki, R. \& Nateghi, A. Optimization of ultrasonic-assisted extraction of natural antioxidants from rice bran using response surface methodology. Ultrasonics Sonochemistry 18, 1279-1286, doi:http://dx.doi.org/10.1016/j.ultsonch.2011.05.004 (2011).

23 Baş, D. \& Boyacı, İ. H. Modeling and optimization I: Usability of response surface methodology. Journal of Food Engineering 78, 836-845, doi:http://dx.doi.org/10.1016/j.jfoodeng.2005.11.024 (2007).

24 Bezerra, M. A., Santelli, R. E., Oliveira, E. P., Villar, L. S. \& Escaleira, L. A. Response surface methodology (RSM) as a tool for optimization in analytical chemistry. Talanta 76, 965-977, doi:http://dx.doi.org/10.1016/j.talanta.2008.05.019 (2008).

25 Li, H.-Z. et al. Optimization of ultrasound-assisted extraction of phenolic compounds, antioxidants and rosmarinic acid from $F$. perilla leaves using response surface methodology. Food Science and Technology (Campinas) 36, 686-693 (2016).

26 Chen, M., Zhao, Y. \& Yu, S. Optimisation of ultrasonic-assisted extraction of phenolic compounds, antioxidants, and anthocyanins from sugar beet molasses. Food Chemistry 172, 543-550, doi:http://dx.doi.org/10.1016/j.foodchem.2014.09.110 (2015).

27 Mohammedi, Z. \& Atik, F. Impact of solvent extraction type on total polyphenols content and biological activity from Tamarix aphylla (L.) Karst. International Journal of Pharma and Bio Sciences 2, 609-615 (2011).

28 Gorinstein, S. et al. A comparative study of phenolic compounds and antioxidant and antiproliferative activities in frequently consumed raw vegetables. European Food Research and Technology 228, 903-911, doi:10.1007/s00217-008-1003-y (2009).

29 Teixeira, D. M., Canelas, V. C., do Canto, A. M., Teixeira, J. \& Dias, C. B. HPLC$\mathrm{DAD}$ quantification of phenolic compounds contributing to the antioxidant activity of 
Maclura pomifera, Ficus carica and Ficus elastica extracts. Analytical Letters 42, 2986-3003 (2009).

30 Wang, M., Liu, J.-R., Gao, J.-M., Parry, J. W. \& Wei, Y.-M. Antioxidant activity of Tartary buckwheat bran extract and its effect on the lipid profile of hyperlipidemic rats. Journal of agricultural and food chemistry 57, 5106-5112 (2009).

1 Bartnick, D., Mohler, C. \& Houlihan, M. ( United States Patent Application, 20060088627, April 27, 2006).

Wang, L., Wang, Z. \& Li, X. Optimization of ultrasonic-assisted extraction of phenolic antioxidants from Malus baccata (Linn.) Borkh. using response surface methodology. Journal of Separation Science 36, 1652-1658, doi:10.1002/jssc.201300062 (2013).

33 Zhou, K. \& Yu, L. Effects of extraction solvent on wheat bran antioxidant activity estimation. LWT - Food Science and Technology 37, 717-721, doi:http://dx.doi.org/10.1016/j.lwt.2004.02.008 (2004).

34 Shahinuzzaman, M. et al. In vitro antioxidant activity of Ficus carica L. latex from 18 different cultivars. Scientific reports 10, 1-14 (2020).

35 Kamarudin, N. A., Markom, M. \& Latip, J. Effects of solvents and extraction methods on herbal plants phyllanthus niruri, orthosiphon stamineus and labisia pumila. Indian Journal of Science and Technology 9, 1-5 (2016).

36 Nath, A. \& Chattopadhyay, P. K. Optimization of oven toasting for improving crispness and other quality attributes of ready to eat potato-soy snack using response surface methodology. Journal of Food Engineering 80, 1282-1292, doi:http://dx.doi.org/10.1016/j.jfoodeng.2006.09.023 (2007).

37 Sin, H. N., Yusof, S., Sheikh Abdul Hamid, N. \& Rahman, R. A. Optimization of enzymatic clarification of sapodilla juice using response surface methodology. Journal $\begin{array}{llll}\text { of } & \text { Food } & \text { Engineering }\end{array}$ doi:http://dx.doi.org/10.1016/j.jfoodeng.2005.01.031 (2006).

38 Yin, X., You, Q. \& Jiang, Z. Optimization of enzyme assisted extraction of polysaccharides from Tricholoma matsutake by response surface methodology. Carbohydrate Polymers

86, 1358-1364, doi:http://dx.doi.org/10.1016/j.carbpol.2011.06.053 (2011).

39 Yang, B., Zhao, M., Shi, J., Yang, N. \& Jiang, Y. Effect of ultrasonic treatment on the recovery and DPPH radical scavenging activity of polysaccharides from longan fruit pericarp. Food Chemistry 106, 685-690, doi:http://dx.doi.org/10.1016/j.foodchem.2007.06.031 (2008). 
140 Shahinuzzaman, M. et al. Optimization of extraction parameters for antioxidant and total phenolic content of Ficus carica L. latex from White Genoa cultivar. Asian J. Chem 31, 1859-1865 (2019).

41 Ilaiyaraja, N., Likhith, K. R., Sharath Babu, G. R. \& Khanum, F. Optimisation of extraction of bioactive compounds from Feronia limonia (wood apple) fruit using response surface methodology (RSM). Food Chemistry 173, 348-354, doi:http://dx.doi.org/10.1016/j.foodchem.2014.10.035 (2015). Shirzad, H., Niknam, V., Taheri, M. \& Ebrahimzadeh, H. Ultrasound-assisted extraction process of phenolic antioxidants from Olive leaves: a nutraceutical study using RSM and LC-ESI-DAD-MS. Journal of Food Science and Technology 54, 2361-2371, doi:10.1007/s13197-017-2676-7 (2017).

Şahin, S. \& Şaml1, R. Optimization of olive leaf extract obtained by ultrasound-assisted extraction with response surface methodology. Ultrasonics Sonochemistry 20, 595-602, doi:http://dx.doi.org/10.1016/j.ultsonch.2012.07.029 (2013).

Karacabey, E. \& Mazza, G. Optimisation of antioxidant activity of grape cane extracts using response surface methodology. Food Chemistry 119, 343-348, doi:http://dx.doi.org/10.1016/j.foodchem.2009.06.029 (2010).

5 Prasad, K. N. et al. Response surface optimisation for the extraction of phenolic compounds and antioxidant capacities of underutilised Mangifera pajang Kosterm. peels. Food Chemistry 128, 1121-1127, doi:http://dx.doi.org/10.1016/j.foodchem.2011.03.105 (2011).

Spigno, G., Tramelli, L. \& De Faveri, D. M. Effects of extraction time, temperature and solvent on concentration and antioxidant activity of grape marc phenolics. Journal of Food Engineering 81, 200-208, doi:http://dx.doi.org/10.1016/j.jfoodeng.2006.10.021 (2007).

Contreras, M. d. M., Arráez-Román, D., Fernández-Gutiérrez, A. \& Segura-Carretero, A. Nano-liquid chromatography coupled to time-of-flight mass spectrometry for phenolic profiling: A case study in cranberry syrups. Talanta 132, 929-938, doi:http://dx.doi.org/10.1016/j.talanta.2014.10.049 (2015).

Ammar, S., Contreras, M. d. M., Belguith-Hadrich, O., Bouaziz, M. \& SeguraCarretero, A. New insights into the qualitative phenolic profile of Ficus carica L. fruits and leaves from Tunisia using ultra-high-performance liquid chromatography coupled to quadrupole-time-of-flight mass spectrometry and their antioxidant activity. RSC Advances 5, 20035-20050, doi:10.1039/C4RA16746E (2015). 
149 Ammar, S., del Mar Contreras, M., Belguith-Hadrich, O., Segura-Carretero, A. \& 2 Bouaziz, M. Assessment of the distribution of phenolic compounds and contribution to the antioxidant activity in Tunisian fig leaves, fruits, skins and pulps using mass spectrometry-based analysis. Food \& Function 6, 3663-3677, doi:10.1039/C5FO00837A (2015).

650 Vallejo, F., Marín, J. \& Tomás-Barberán, F. A. Phenolic compound content of fresh and dried figs (Ficus carica L.). Food Chemistry 130, 485-492 (2012).

851 Cádiz-Gurrea, M. L. et al. Isolation, comprehensive characterization and antioxidant activities of Theobroma cacao extract. Journal of Functional Foods 10, 485-498, doi:http://dx.doi.org/10.1016/j.jff.2014.07.016 (2014).

52 Pérez-Jiménez, J. \& Torres, J. L. Analysis of proanthocyanidins in almond blanch water by HPLC-ESI-QqQ-MS/MS and MALDI-TOF/TOF MS. Food Research International 49, 798-806, doi:http://dx.doi.org/10.1016/j.foodres.2012.09.005 (2012).

1453 Wei, S., Wu, W. \& Ji, Z. New antifungal pyranoisoflavone from Ficus tikoua Bur. International Journal of Molecular Sciences 13, 7375 (2012). Bankeu, J. J. K. et al. Isoflavone dimers and other bioactive constituents from the Figs of Ficus mucuso. Journal of Natural Products 74, 1370-1378, doi:10.1021/np100896w (2011).

Aida, M., Hano, Y. \& Nomura, T. Ficusins A and B, two new cyclic-monoterpenesubstituted isoflavones from Ficus septica Barm. Heterocycles 12, 2761-2768 (1995). M. Boland, G. \& M. X. Donnelly, D. Isoflavonoids and related compounds. Natural Product Reports 15, 241-260, doi:10.1039/A815241Y (1998). 
Figures

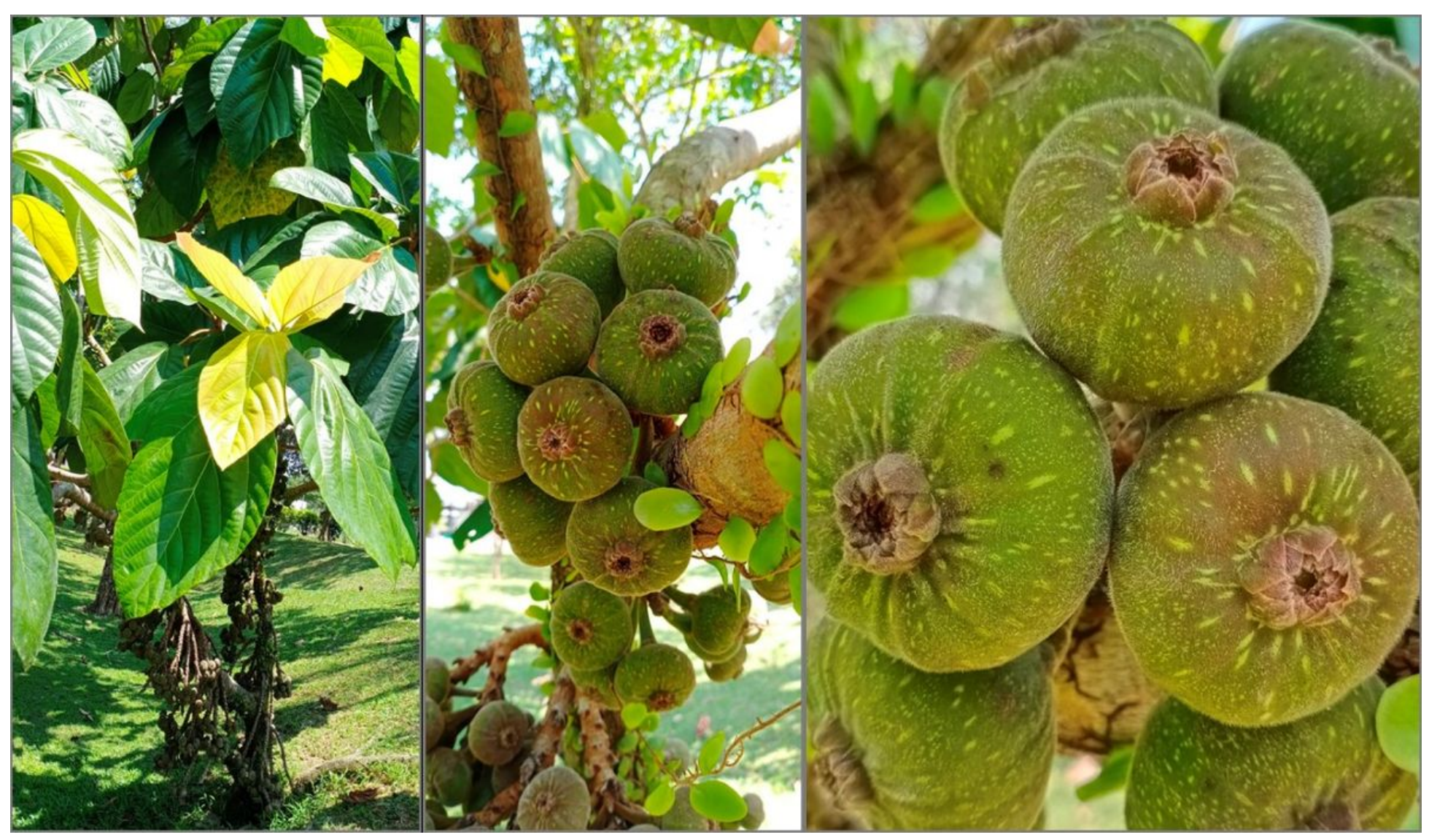

Figure 1

Fresh fruits of Ficus auriculate collected from UKM campus 
(a)

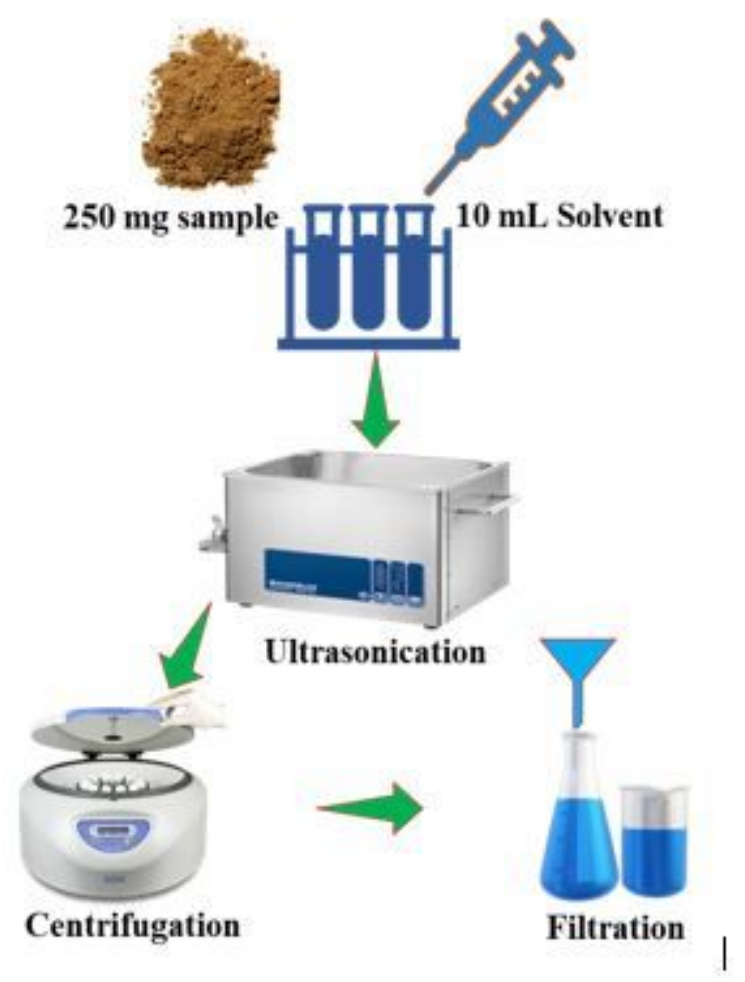

(b)

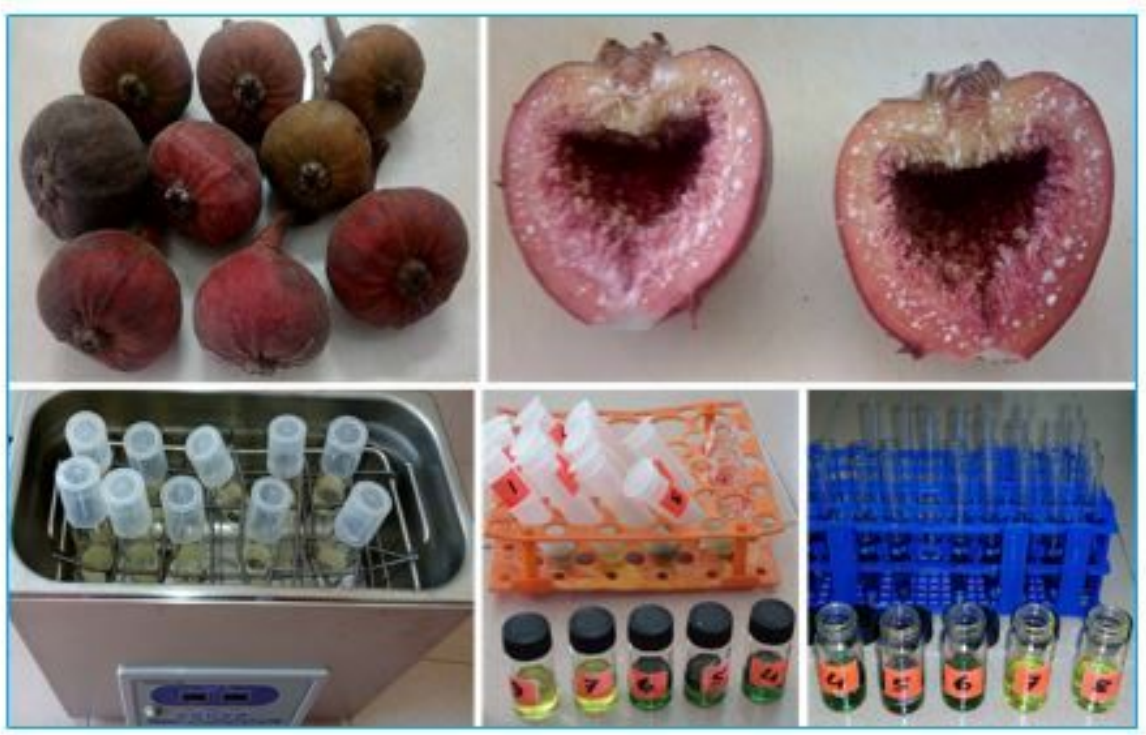

Figure 2

a) Schematic diagram for extraction and b) Extraction process of antioxidant active compounds from $\mathrm{F}$. auriculata fruits 


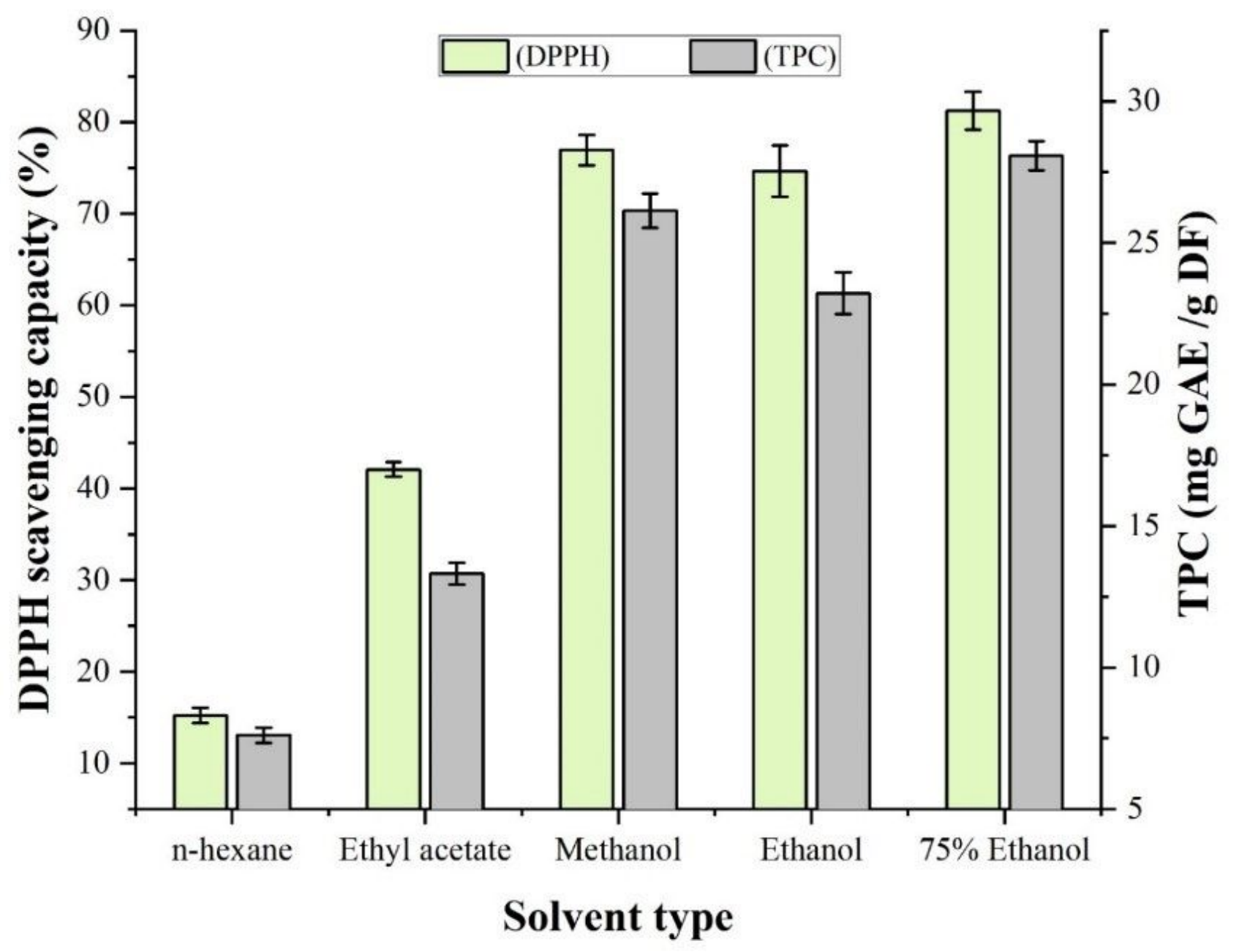

Figure 3

Effect of solvent on the antioxidant activity and TPC of fruits of Ficus auriculata. 


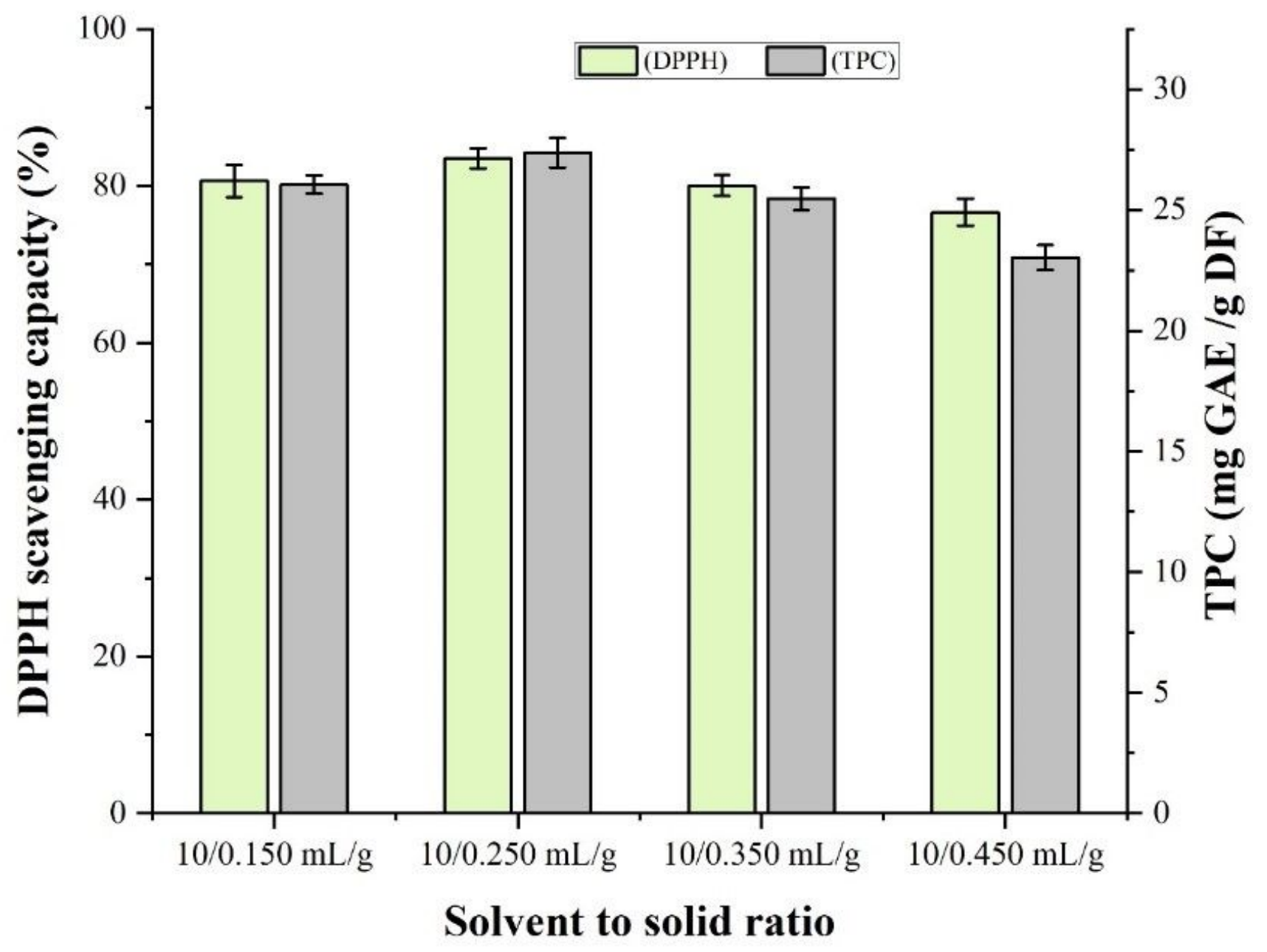

Figure 4

Effect of solvent to solid ratio on the antioxidant and TPC of fruits of Ficus auriculata extracted with 75\% ethanol. 

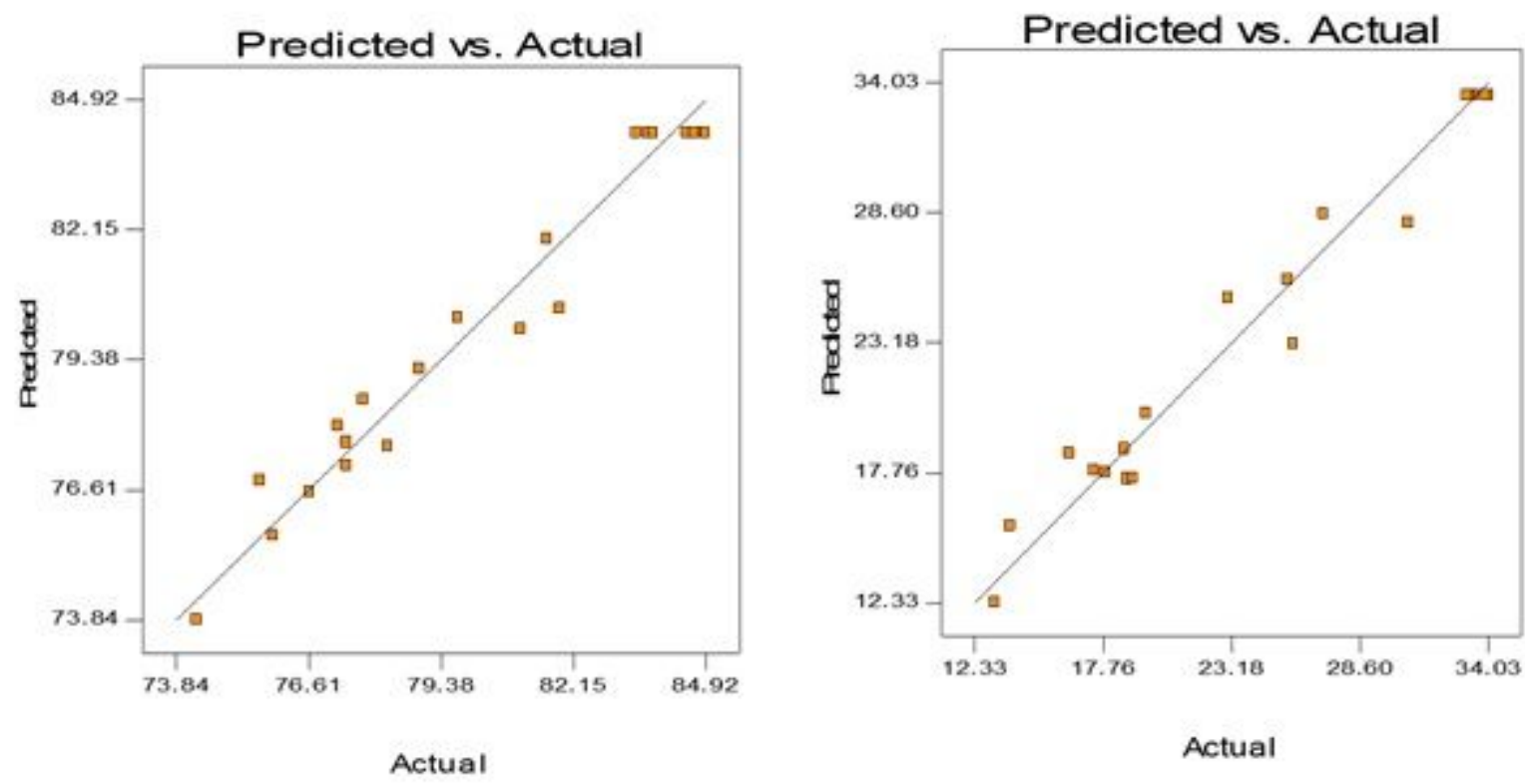

Figure 5

Predicted vs Actual values curve for Antioxidant activity and TPC of F. auriculata fruit extract 


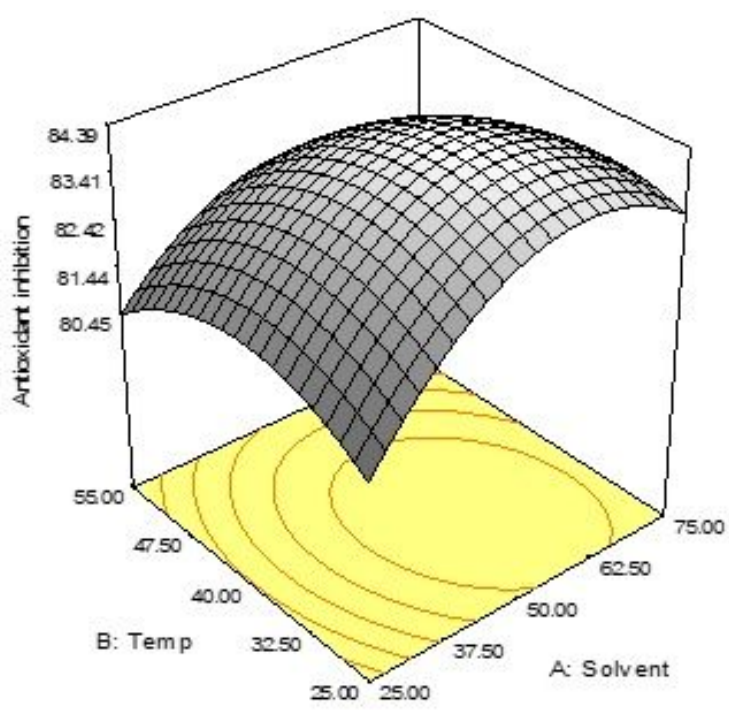

(a)

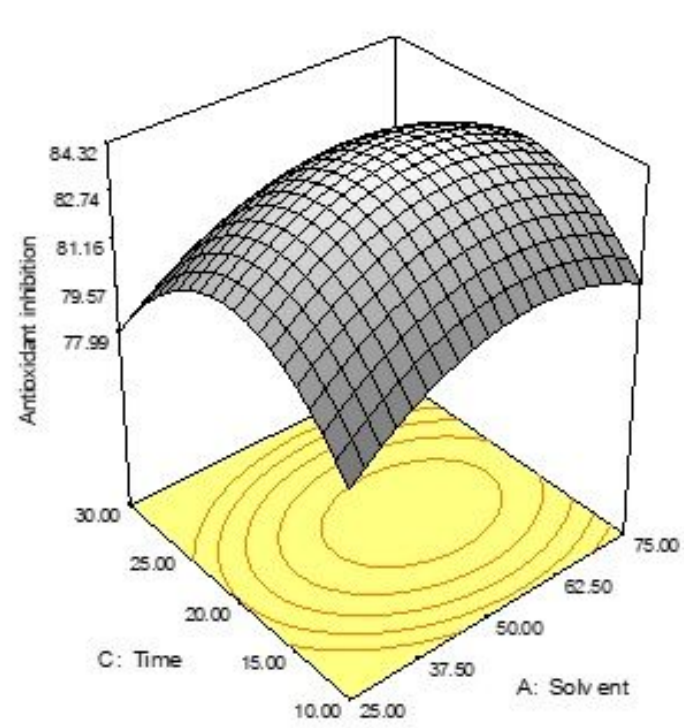

(b)

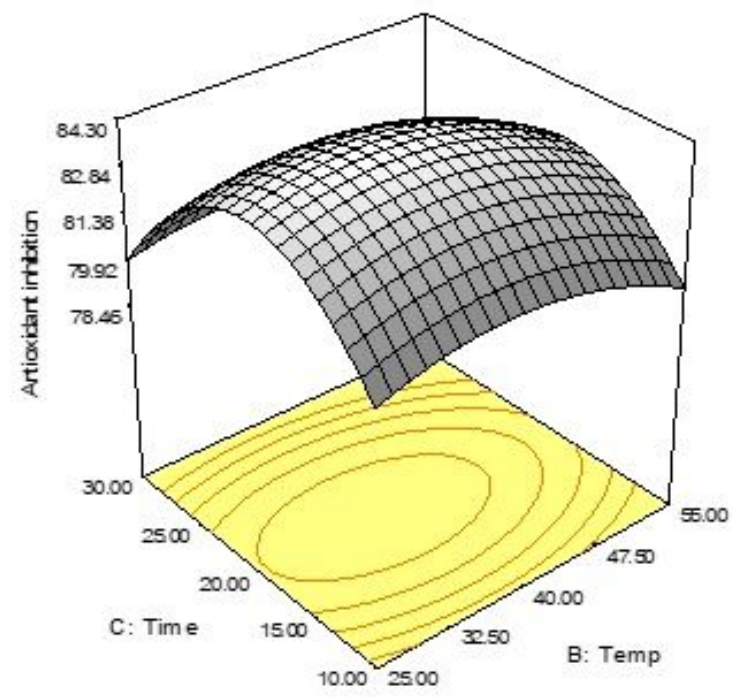

(c)

\section{Figure 6}

Response surface plots showing the effects of extraction parameters on the DPPH of the extracts from fruits of F. auriculata. (a) The constant ultrasonic time (20 $\mathrm{min})$, (b) the constant temperature $\left(40^{\circ} \mathrm{C}\right)$, and (c) the constant ethanol concentration (50\%). 


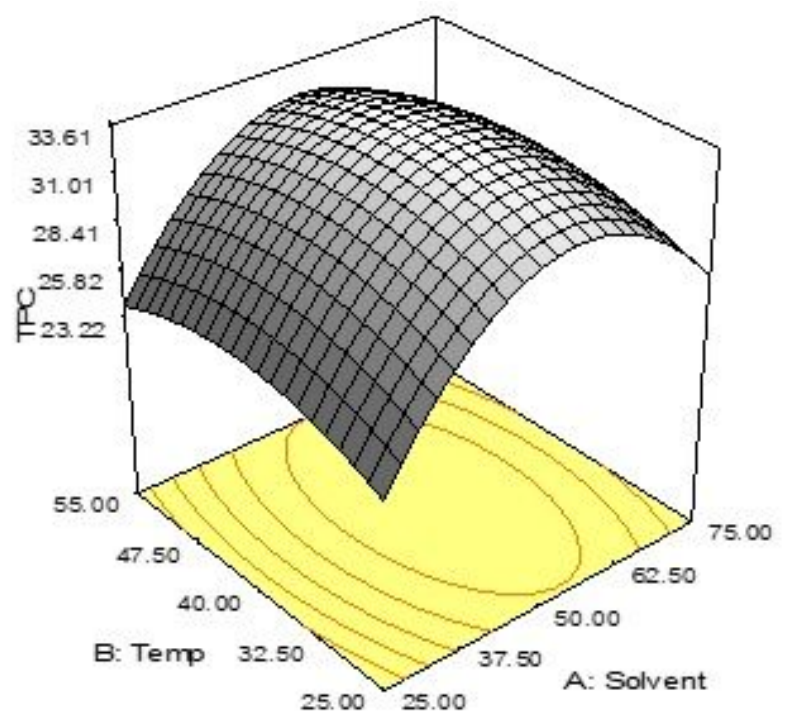

(a)

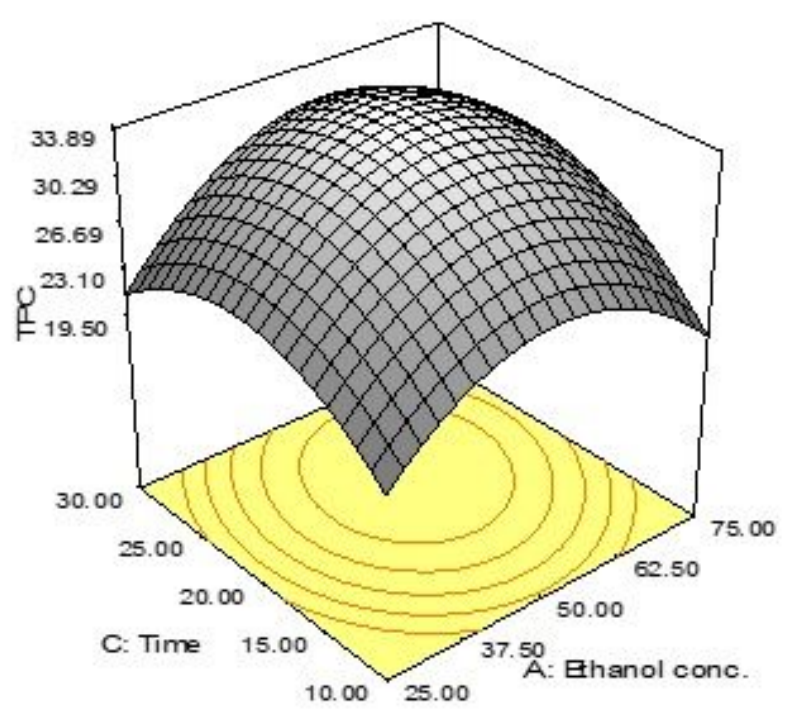

(b)

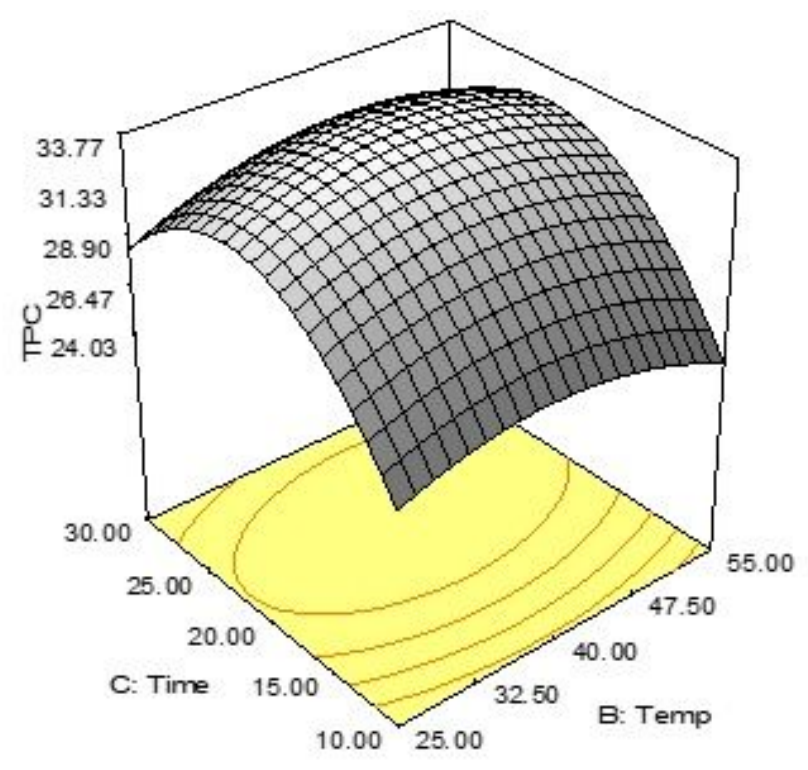

(c)

\section{Figure 7}

Response surface plots showing effects of ethanol concentration, temperature and sonication time on total phenolic contents of the extracts from fruits of F. auriculata. (a) The constant ultrasonic time (20 $\min )$, (b) the constant extraction temperature $\left(40^{\circ} \mathrm{C}\right)$, and (c) the constant ethanol concentration $(50 \%)$. 


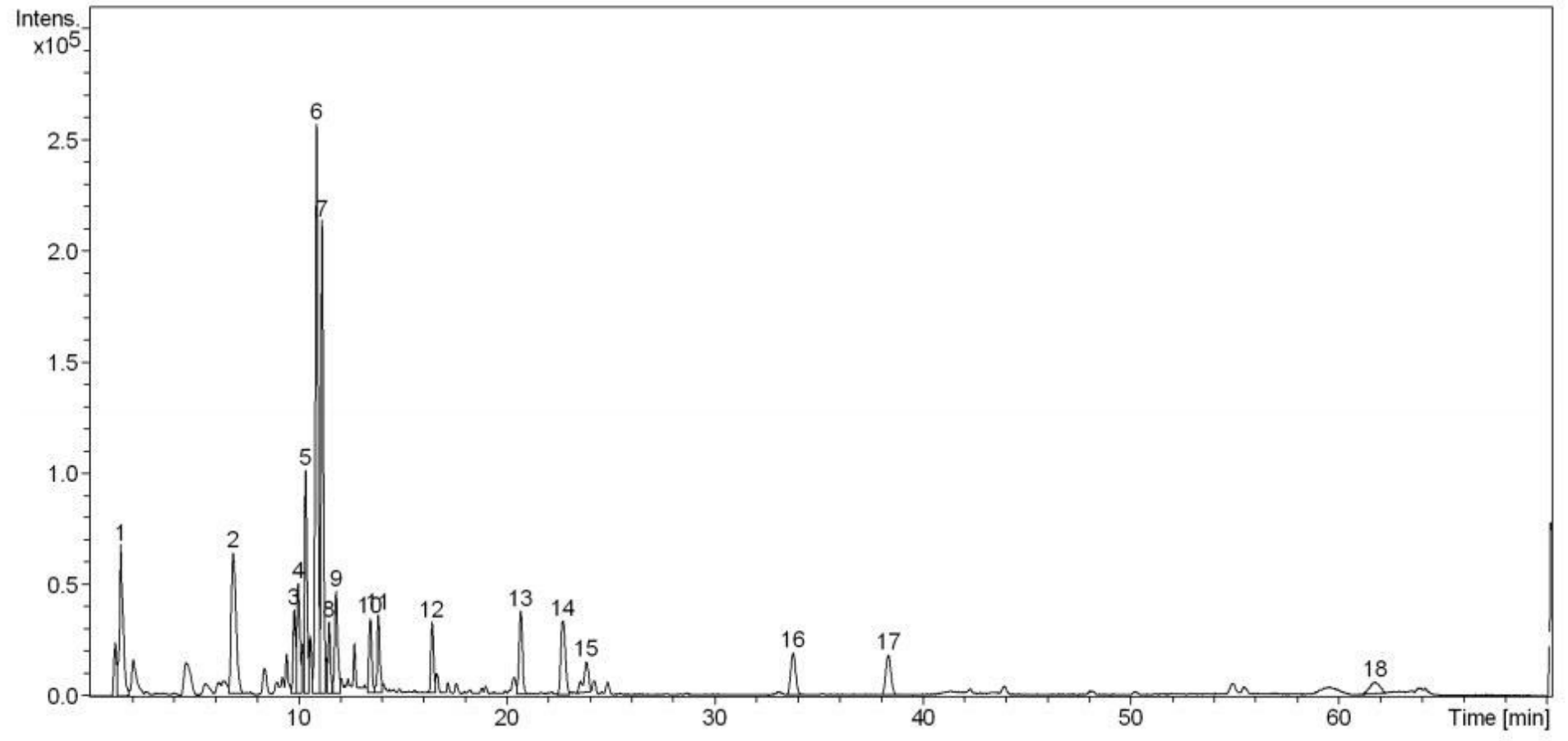

Figure 8

LC-MS fingerprinting analysis of fruits of F. auriculata analysed in the negative ionization mode. 